IZA DP No. 6778

Education and Fertility:

Evidence from a Policy Change in Kenya

Luke Chicoine

August 2012

Forschungsinstitut

zur Zukunft der Arbeit

Institute for the Study

of Labor 


\title{
Education and Fertility: Evidence from a Policy Change in Kenya
}

\author{
Luke Chicoine \\ DePaul University \\ and IZA
}

\section{Discussion Paper No. 6778 \\ August 2012}

IZA
P.O. Box 7240
53072 Bonn
Germany

Phone: +49-228-3894-0

Fax: +49-228-3894-180

E-mail: iza@iza.org

Any opinions expressed here are those of the author(s) and not those of IZA. Research published in this series may include views on policy, but the institute itself takes no institutional policy positions.

The Institute for the Study of Labor (IZA) in Bonn is a local and virtual international research center and a place of communication between science, politics and business. IZA is an independent nonprofit organization supported by Deutsche Post Foundation. The center is associated with the University of Bonn and offers a stimulating research environment through its international network, workshops and conferences, data service, project support, research visits and doctoral program. IZA engages in (i) original and internationally competitive research in all fields of labor economics, (ii) development of policy concepts, and (iii) dissemination of research results and concepts to the interested public.

IZA Discussion Papers often represent preliminary work and are circulated to encourage discussion. Citation of such a paper should account for its provisional character. A revised version may be available directly from the author. 
IZA Discussion Paper No. 6778

August 2012

\section{ABSTRACT}

\section{Education and Fertility: Evidence from a Policy Change in Kenya*}

This paper investigates the relationship between women's education and fertility by exploiting a 1985 policy change in Kenya that lengthened primary school by one year. An instrumental variables approach measures the exogenous variation in treatment intensity across birth cohorts. The reform led to an increase in education, a delay in marriage, and reduced fertility beginning at the age of 20 . The effect on fertility becomes increasingly negative through age 25. The findings suggest that postponement of marriage, reduction in the marital education gap, and increased early use of modern contraceptives contribute to reduced fertility. These results are consistent with women having greater control over their fertility decision.

JEL Classification: $\quad$ O15, J13, 125

Keywords: fertility, education, Kenya

Corresponding author:

Luke Chicoine

Department of Economics

DePaul University

1 East Jackson Blvd, Suite 6200

Chicago, IL 60604

USA

E-mail: Ichicoin@depaul.edu

\footnotetext{
* I would like to thank Bill Evans, Jim Sullivan, Joe Kaboski, Molly Lipscomb, Julian Cristia, Seema Jayachandran, Jason Lindo, Robert Tamura, and the participants of the microeconomics seminar at the University of Notre Dame for their helpful comments and advice. I also thank the Kellogg Institute for International Studies for their support. Remaining errors are my own.
} 


\section{Introduction}

Over the past two decades the international community has led a concentrated effort to promote the education of young women throughout the world. This is highlighted by the Millennium Development Goals' prominent inclusion of objectives targeting equal school enrollment and literacy parity for girls, and in 2000, the establishment of the United Nations Girl's Education Initiative (UNGEI), whose mission is to ensure young women have the opportunity to receive a quality education. An explicit objective of these efforts is to reduce the birth rates of low income populations. As noted by Dr. Sadia Chowdhury, a reproductive and child health specialist at the World Bank, "Promoting girls' and women's education and the opportunity to succeed are just as important in reducing birth rates in the long run as promoting contraception and family planning."1 This renewed push for the reduction of population growth and fertility, through education, emphasizes the importance of examining whether increases in schooling have lasting impacts on fertility, and the channels through which such a relationship may occur.

This paper exploits an increase in education generated by a 1985 schooling reform in Kenya to examine the effect of education on fertility and related behavior. The key element of the reform was that it required students to complete eight years of primary education, an increase from the previous seven years, before being eligible to earn the certificate of primary education. This had the effect of adding an additional year of schooling for all students who completed only primary school, and also generated an extra year of education for students who continued on to secondary school. The scale of the reform allows for the use of a nationally representative sample. I use data from five rounds of the Demographic and Health Survey (DHS) conducted in Kenya, this generates a large sample of nearly 20,000 Kenyan women born between 1950 and 1980. The reform's timing, along with these data, enables a thorough investigation of its effect on Kenyan women into their mid-twenties.

\footnotetext{
${ }^{1}$ The inverse relationship between education and fertility was largely established from conditional correlations generated by single equation models, which are susceptible to omitted variable bias (Shultz, 1994 and 1998 ; Ainsworth, Beegle, and Nyamete, 1996; Lam and Duryea, 1999). A discussion of the omitted variable bias concern can be found in Becker (1993).
} 
Due to either a delay in entering school or the high level of grade repetition, the effect of the reform's implementation is distributed across many birth cohorts. ${ }^{2}$ Given the continuity in the transition from untreated birth cohorts to treated cohorts, I use an instrumental variable (IV) approach to evaluate the impact of increased schooling. Specifically, I use pre-treatment data to estimate the likelihood of being treated by the reform. This concept is broadly inspired by Angrist and Lavy (1999) and the exact application is similar to the one employed by Borkum (2010) who used the procedure to examine the effect of an increase in education on wages in Botswana.

I show that the reform led to an increase in schooling, and that it substantially affected the outcomes of women. The reform led to postponement of marriage, and lowered the fraction of women who began childbearing at the age of 20 by 8.4 percentage points. More importantly, the effect on total fertility persisted and became increasingly negative at older ages, eventually lowering a woman's fertility by nearly a third of a child at the age of 25 . The reform's effects exhibit heterogeneity even within ethnic communities and groups with similar levels of education, highlighting the importance of this study's broad scope.

In a pair of placebo regressions, I also show that none of the previous results are found for women whose education was not affected by the reform. For example, using data from a subset of women who did not complete five years of education and whose schooling did not increase because of the lengthening of primary school, I find no evidence of a postponement of marriage, or a reduction in fertility. For this group of women, along with additional placebo groups, I am able to demonstrate that the model is not capturing a general change that is occurring throughout the population, but rather an effect that is isolated to Kenyan women who were treated by the reform.

Furthermore, in the years following the reform fertility rates in Kenya began to fall sharply, with cohorts affected by the reform having the largest declines. Beginning in 1974 the Kenyan government, with the support of the international community, implemented its initial family planning effort. These

\footnotetext{
${ }^{2}$ A previous study, Ferre (2009), also attempted to exploit this policy reform. However, the paper did so using a regression discontinuity $(\mathrm{RD})$ design. The dispersion of the reform's impact on education across a number of cohorts makes a regression discontinuity design unsuitable.
} 
efforts established a rural network of health facilities and training schools, and led to near universal knowledge of contraception for women across all cohorts and levels of education. However, for over a decade these programs were largely ineffective; not until after the education reform was implemented did evidence of falling fertility rates emerge (World Bank, 1992; Heisel, 2007). Between 1977 and 1989 the fertility rate in Kenya fell 16 percent, and over 80 percent of that decline occurred after 1984 (World Bank, 1992), and the fall in fertility was most dramatic for the cohorts of women affected by the 1985 extension of primary school.

The breadth of the Kenyan education reform and depth of data available through the DHS enable a uniquely detailed investigation into the potential mechanisms driving the reduction in fertility seen after the reform. I am able to rule out a number of explanations proposed in the literature. The most direct link between schooling and the reduction in a woman's fertility is the "incarceration effect" proposed in Black, Devereux, and Salvanes (2008). This is the idea that while women are in school they do not have the desire or opportunity to have children. The persistence of the reform's effect for older ages and the lack of evidence that more highly educated populations saw a larger reduction in fertility suggest that the incarceration effect is not a significant cause of the decline in fertility. I also find no evidence that the reform impacted the likelihood of a woman ever having a pregnancy terminated.

An increase in a woman's education, such as that generated by the 1985 extension of primary school, could also lead to increased selectivity when finding a partner. This assortative matching (Lavy and Zablotsky, 2011) may then affect fertility outcomes through spousal characteristics. However, I find no evidence that the reform led to a change in the age or education of the husband, or the age difference between a woman and her husband. Furthermore, due to the large age difference between Kenyan women and their husbands over this time period, women whose schooling was affected by the reform often married men who completed their education before the 1985 extension of primary school. This characteristic has the effect of reducing the average marital education gap by over one-third. Although, the DHS does not collect individual or household income data, the increase in schooling likely led to Kenyan women earning a higher share of the household's income (Borkum, 2010), and possibly to greater 
empowerment within the household. The reform led to an increased likelihood of women using modern contraceptives before having their first child, allowing them to postpone childbearing even after marriage. Furthermore, in agreement with Mocan and Cannonier's (2012) findings from Sierra Leone, evidence of increased empowerment for these women is supported by the increased likelihood of being tested for HIV/AIDS. This evidence is also consistent with the findings from Ashraf, Field, and Lee (2010), who demonstrate that access to contraception alone is not enough to reduce fertility for women in Zambia. They find that women only reduce unwanted pregnancies when they are able to make their own personal choice regarding the use of contraception. I find that the postponement in marriage and childbearing, reduction in the marital education gap, increased early use of contraception, and ultimately, the decline in fertility are isolated to women whose level of schooling was positively affected by the 1985 Kenyan education reform.

Previous work using exogenous variation in education in developed settings has found less robust results. Using data from California and Texas, McCrary and Royer (2011) found no evidence that increasing education by beginning school at younger ages reduced fertility. Exploiting changes in compulsory school laws in the U.S. and Norway, Black, Devereux, and Salvanes (2008) found that increased schooling led to a reduction in fertility. However, the results from Monstad, Propper, and Salvanes (2008) suggested that the result in Norway may be evidence that women were only postponing their births from their teens and early twenties to their late thirties. Work by Lavy and Zablotsky (2011) found that increased access to school in parts of Israel due to the end of military rule led to decreased fertility for Arab women.

The literature focusing on the effect in developing countries suggests a larger and more prevalent effect of education on fertility, as may be expected. In Indonesia, Breierova and Duflo (2004) found mixed evidence of education's effect on fertility. They estimated that increased levels of primary education generated by a large-scale school construction project led to fewer births for women by the age of 15 , but had no effect on the number of children born to women by the age of 25 . However, they found evidence that the increase in maternal schooling led to reduced levels of child mortality. More robust 
evidence was discovered in Nigeria, where Osili and Long (2008) found that the expansion of universal primary education led to reductions in fertility for women at the age of 25 .

Given its focus on Kenya, this paper is most closely related to the work of Duflo, Dupas, and Kremer (2011). They conducted a field experiment in Western Kenya where they provided free uniforms to girls in the sixth grade of primary school. This lowered the cost of education and increased schooling for girls treated by the intervention. They found evidence that the program led to a reduction in marriage and fertility, but the results for risky sexual behavior were not as robust. Their estimates for fertility are large for the modest increase in education provided by the reform. I find similar results, but for a nationally representative population, for a policy reform that is easy to replicate, and I am also able to examine the effects over a longer period of a woman's life. More importantly, I examine in detail the pathways through which increased education impacts fertility.

The paper proceeds as follows. The 1985 reform is explained in greater detail in section II. The data are described in section III. The empirical model and instrument used to estimate the effect of the reform on education and fertility is presented in section IV. The results are discussed in section V, and section VI concludes.

\section{Education Reform in Kenya, 1985}

\section{a. 1985 Education Reform: Change in the Education Structure}

In January 1985, Kenya restructured their education system. The new 8-4-4 system consisted of eight years of primary school, followed by four years of secondary school, and four years of tertiary education. This system replaced the 7-4-2-3 structure that had been in place since Kenya gained its independence. The previous education structure included seven years of primary education, followed by four years of "lower secondary" education, two years of "upper secondary," and finally three years of university.

The reform was implemented nationally in January 1985, the beginning of the school year. This was functionally executed by admitting no class of students to secondary school in 1985 . The class of 
students who completed their seventh year of primary school in 1984 would have normally proceeded to secondary school in the following year. However, due to the restructuring of the education system these students remained in primary school for an eighth year. The last pre-reform class of students was the class that completed their primary school exam in 1983 and progressed into secondary school through the old system in 1984.

As shown in Figure 1, this reform lengthened the time a student needed to stay in primary school before becoming eligible to obtain a certificate of primary education from seven to eight years. ${ }^{3}$ The length of the principal stage of secondary school remained four years; students who ended their education during or directly after the completion of secondary school also received an extra year of education due to the additional year in primary school. Students completing four years of secondary education completed 11 years of school prior to the reform, and 12 years of school after the reform. The reform had no clear effect on years of schooling for students who continued their education beyond four years of secondary school, three quarters of pre-reform students who completed "upper secondary" school continued to tertiary education, and students who earned their college degree completed 16 years of schooling under both education systems.

There are additional characteristics of the reform that may have had smaller adverse effects on educational attainment. First, adding an additional year of primary school may have simply reduced the number of students moving from primary school to secondary school due to increased attrition. Second, the reform put added stress on primary schools with an additional 320,000 students attending primary school in 1985 (Kenya Ministry of Education, 1988). Schools responded by hiring roughly 16,000 additional teachers, leading to lower student-teacher ratios in 1985 compared to the previous years; however, most of the new teachers were untrained (O'Eiseman, 1988; Kenya Ministry of Education, 1988; Somerset, 2009). The increase in the size of the student body and unprepared teachers likely had the effect of initially reducing the quality of the extra year of education. The extra year of primary school

\footnotetext{
${ }^{3}$ Prior to the reform, the Certificate of Primary Education (CPE) examination was given after the seventh grade of primary school. After the reform, the test was renamed the Kenya Certificate of Primary Education (KCPE) and administered after eighth grade.
} 
may have deterred students from completing their primary education, and the lower quality of teaching possibly reduced the human capital accrued during the additional year.

\section{b. Concurrent and Prior Education Reforms in Kenya}

The reform also led to a redesign of the curriculum that was taught in Kenyan schools. The new curriculum was structured with the understanding that the primary level of education was likely to be the terminal level of schooling for many students, and encouraged skills that could be used as soon as they left the education system (Rharade, 1997). ${ }^{4}$ Hasty implementation of the reform meant inadequate teacher training and that syllabi were prepared in less than a month (O'Eisemon, 1988). Furthermore, in 1990 less than a quarter of primary schools had the workshops required to complete the technical training included in the updated curriculum (O'Eiseman, 1988).

It is also important to take into account that the likelihood an individual from a given cohort was affected by the 1985 reform is strongly linked to two primary school fee reductions in the 1970s. In 1974, primary school entrance fees were abolished for grades one through four, and each successive year the abolishment of fees was extended to the next grade. (Nkinyangi, 1982; Somerset, 2009; Ohba 2009). This led to a one time increase in enrollment in 1974, but the increase quickly dissipated due to overcrowding, which led to a lower quality of education and increases in alternative fees levied by many schools (Nkinyangi, 1982; Somerset, 2009). The alternative school fees that had been implemented in response to the increased demand for education from the 1974 abolishment of fees were banned in 1979. The 1979 ban on additional school fees required community groups to raise the additional funds, and did not allow direct fees to be collected from the student's families (Somerset, 2009; Ohba, 2009). The 1979 reform again led to a large increase in primary school enrollment, but after the 1979 reform, enrollment rates remained at similar levels in the subsequent years. These reforms greatly affected the timing of when students began, or possibly continued, their education. This had a significant impact on the probability of

\footnotetext{
${ }^{4}$ Family planning and sex education were not subjects included in the introduced curriculum (Kenya Ministry of Education, 1986 and 1988).
} 
a student advancing to secondary school before the 1985 reform was implemented. These fee reductions are taken into account when calculating a cohort's likelihood of being affected by the 1985 reform.

\section{Data}

a. Sources

All individual level data are from five rounds of the Demographic and Health Surveys (DHS) conducted in Kenya: 1989, 1993, 1998, 2003, and 2008. I use data from two of the DHS datasets. The individual women's dataset provides detailed personal information regarding birth date, age of marriage and first intercourse, as well as information regarding contraceptive use. Demographic characteristics such as ethnicity and retrospective data on the type of location lived in during their childhood (urban/town/rural) are also included. The births' data are retrospective information encompassing the respondent's complete birth history. I exploit the information gathered on the age of the mother at each birth to determine the number of births a woman has by any given age. Only women born between 1950 and 1980 are included in the sample.

In addition to the restrictions on birth cohorts, the analysis sample includes respondents who report both their birth year and birth month. This is essential to correctly identifying the effect of the reform due to the fact that the likelihood of treatment is assigned based on the woman's time of birth. Individuals who report their date of birth information are on average a year younger, with about twotenths fewer children by age 25 , and a year more of school. ${ }^{5}$

Summary statistics for the sample used in this paper are shown in Table 1. The average respondent included in this paper's sample is 28 years old with seven and a half years of education.

Woman in the sample, on average, began sexual activity before the age of 17, followed by marriage, before giving birth to their first child shortly after the age of 19. Large fractions of women are married

${ }^{5}$ The results for the full sample are similar to the results found in this paper for the sample of respondents with complete date of birth information. When date of birth data are missing, the DHS attempts to estimate the correct month or year of birth using other information collected in the survey. The inclusion of observations with imputed month or year data only introduces some inconsistency across outcome variables for younger ages. Estimates for the full sample are shown in the appendix. 
and have their first child between the ages of 19 and 21; the largest increase in the fraction of women becoming sexually active is between the ages of 16 and 18. Finally, women included in the sample have an average of about two and a half births by the age of 25 .

I also use school enrollment and failure rate data from the World Bank's Education Statistics and UNESO's Institute for Statistics, information on the age of students enrolled in grade one in 1978 and 1979 from Somerset (2007), and transition rates from the last year of primary school to secondary school from Ohba (2009). This information allows me to estimate the likelihood that a student progresses through primary school and into secondary school before the 1985 reform. These data are explained in more detail below.

\section{b. Measuring Schooling}

Measuring an individual's level of educational attainment is critical to this project. Although the DHS has a two-question approach to measure an individual's highest completed level of schooling, its method is unable to accurately capture the exact number of years of schooling for some key cohorts used in the analysis. The DHS records the highest education level an individual attended. This can be seen in Panel A of Table 2. Then the DHS records the highest year of education completed at that level, Panel B. The years of education are then calculated combining these two variables. If an individual completes five years of primary school, the years of schooling variable will be equal to five years. The modal number of years of secondary school completed both before and after the reform is four years. This is the length of "lower secondary" in the pre-reform period and the length of secondary school in the post-reform period (e.g., see Figure 1). If an individual reports having completed four years of secondary school, their total years of schooling is equal to the four years of secondary school plus the number of years of primary school completed. This means that the number of total years of school is dependent on whether the respondent completed primary school before or after the reform, but this information is not included in the data. Therefore, an individual who reports having completed four years of secondary school could 
have completed either 11 years of school (pre-reform, with seven years of primary school), or 12 years of school (post-reform, with eight years of primary school).

All individuals born after 1971 are by construction required to complete eight years of primary school to be eligible for the Kenyan Certificate of Primary Education exam. Likewise, virtually all individuals born before 1964 were eligible for the equivalent exam after only seven years of education. However, for the cohorts in between, it is not possible to determine whether respondents who continued their education beyond primary school completed seven or eight years of primary school. Subsequently, the traditional "years of education" variable does not accurately measure schooling for all respondents.

Given these limitations, I construct two alternate measures of educational attainment. First, I can identify individuals whose highest level of schooling is the eighth year of primary school. I do this using the variables described in Table 2, "education level" in Panel A and "education years" in Panel B. The variable, Education8, can be defined in the following way:

$$
\text { Education }_{i}= \begin{cases}1 & \text { if education level }=1 \text { and education years }=8 \\ 0 & \text { otherwise }\end{cases}
$$

Only individuals who complete primary school after the 1985 reform will have completed eight years of primary school. This variable is graphed in Figure 2, for each birth quarter from the first quarter of 1950 through the last quarter of 1980. The figure is separated into three sections: post-reform, transition, and pre-reform. The triangles in the post-reform period represent the fraction of women born in a given quarter whose highest level of education was eight years of primary school. The squares represent the same information for the transition birth quarters, and the diamonds in the pre-form period. The graph is the most direct representation of the differential impact of the reform across birth cohorts. The first post-reform cohort is the cohort born in 1972. Individuals in this cohort may begin their schooling as early as the year they turn six, 1978, and if the student graduates on time would reach the seventh grade in 1984. Due to late entry into school and high repetition rates there are seven transition cohorts whose likelihood of being affected by the reform increases the closer their birth year is to 1972 . 
It is also possible to correctly identify if a student completes at least eight years of schooling.

$$
\text { AtLeast } 8_{i}=\left\{\begin{array}{l}
1 \text { if education level }=1 \text { and education years }=8 \\
1 \text { if education level }=2 \text { and education years } \geq 1 \\
1 \text { if education level }=3 \\
0 \quad \text { otherwise }
\end{array}\right.
$$

Any student who completes at least his first year in secondary school would also have completed at least seven years of primary school. This variable, plotted in Figure 3, captures the reform's effectiveness in increasing the education of primary completers, those who would have had seven years of schooling before the reform but completed eight years of school after the reform, but does not take into account that all students who completed between one and four years of secondary school also gained an extra year of schooling. As can been seen in Figure 3, the fraction of students completing at least eight years of school increases at a much faster rate for the birth cohorts of the transition period, the slope of the transition trend line is nearly twice as steep as the trend line of pre-reform period.

\section{Methodology}

\section{a. Baseline Estimates via Ordinary Least Squares}

As discussed in the introduction, the previous literature has established a negative relationship between fertility and education (Schultz, 1994 and 1998; Ainsworth, Beegle, and Nyamete, 1996; Lam and Duryea, 1999). I begin by demonstrating that this relationship exists within Kenya for individuals born between 1950 and 1980. This is done by estimating an ordinary least squares (OLS) model. In the initial specification, years of schooling, $y r s c h l_{i c}$, is used as an individual's measure of education, although as noted above, this variable is measured with some noise for the transition birth cohorts. The model estimated is defined by the equation

$$
y_{i c}=\alpha+\operatorname{yrschl}_{i c} \beta+\sum_{p=1}^{3} a g e_{i c}^{p} \pi_{p}+\sum_{n=1}^{2} \operatorname{qtrend}_{c}^{n} \varphi_{n}+X_{i c} \theta+\varepsilon_{i c}
$$


for some outcome $y$, for individual $i$, from birth cohort $c$, defined by a specific birth year and quarter. The variable age $_{i c}$ is the respondent's age at the time of the survey. A quarterly trend in birth year and quarter, qtrend $_{c}$, is also included. ${ }^{6} X_{i c}$ is a vector of individual level covariates, including fixed effects for quarter of birth, ethnicity, and childhood place of residence (city/town/rural). These covariates are either constant over an individual's life or occur prior to schooling decisions being made, which leaves few available variables. Estimates are weighted using sampling weights provided by the DHS, and standard errors are clustered at the birth cohort (birth year and quarter) level.

Before estimating equation (3), it is useful to provide a visual display that establishes an expectation for what the results will yield. To do this, I focus on the underlying issue being examined in this paper, total fertility. In Figure 4, I plot the total fertility for women at age 25 for each birth year and quarter combination. Only women age 26 and older are included in the figure. As with the previous figures, Figure 4 is separated into three periods. In Figure 4, the slope of the transition period is more than 30 percent steeper than the slope in the pre-treatment period. This is consistent with the change in schooling seen in Figure 2 and Figure 3; the slope of the transition period is steeper than the pre-treatment period, leading to accelerated reductions in fertility prior to the post-reform period. This pattern establishes an unconditional inverse relationship between the increase in education caused by the reform and levels of total fertility.

Expanding beyond Kenya, it is insightful to compare the change in fertility in Kenya to what is occurring in Tanzania over this time period. Although different in many respects, such as income, ethnicity, education, and religion, Tanzania shares a common history with Kenya during this time period. Both nations were former British colonies before gaining their independence in the 1960s, and both nations originally adopted the same schooling system, a system of education that Tanzania still employs to this day. The number of births by age 25 in Tanzania, for each birth quarter, is shown in Figure 5 . Unlike Figure 4 for Kenya, there is no steepening in slope for the transition birth cohorts. In fact, the

\footnotetext{
${ }^{6}$ A quarterly time trend is used in place of an annual trend, due to evidence from the 1993 DHS showing that quarter of birth greatly affects the likelihood that a child is in the highest grade possible for their birth cohort. As will be shown later, the results are robust to various specifications of the trend.
} 
slope for the transition cohorts in Tanzania is becoming increasingly horizontal. East Africa was experiencing a great deal of change over this time period, and the comparison of Figure 4 and Figure 5 demonstrate that the accelerated reduction in fertility that occurred in Kenya during this time was not a region wide phenomenon.

The following estimations for fertility and related variables will establish that the negative relationship between schooling and fertility found in Kenya persists when conditioning on other covariates. Using the model described in equation (3), I estimate the relationship between years of schooling and four outcomes: first intercourse, marriage, and birth, as well as a woman's total fertility. I do this for each age between 15 and 25. In Panel A of Table 3, I show the relationship between schooling and first intercourse. Each cell is a separate regression, and the outcome variable is equal to one if the respondent reported having intercourse before or at the specified age. The number of observations changes due to restricting the sample to include only observations older than the given age. ${ }^{7}$ However, restricting all samples to only observations above 25 years old produces similar results. The results in Panel A suggest a statistically significant negative correlation between schooling and young women becoming sexually active, with the largest negative relationship occurring at age 17 . The results in Panel $\mathrm{B}$ are evidence that there is also a negative relationship between schooling and marriage at each age. In Panel C of Table 3, I show the relationship between schooling and first birth. As with the two previous panels, the estimates are statistically significant across all ages, and a pattern emerges showing that the correlation between schooling and a mother's first birth is most negative at age 19. Finally, the estimates for total number of births at each age are shown in Panel D of Table 3. The correlation between schooling and total fertility becomes increasingly negative at older ages.

The OLS results suggest that as schooling increases women postpone their sexual activity, marriage, and childbearing. The results also suggest that the effect persists and grows even after women leave school. However, these results are likely biased if schooling is correlated with unobservable

\footnotetext{
${ }^{7}$ Panel A has fewer observations because some women chose not to report at what age they became sexually active. Furthermore, observations were also dropped if a woman reported having a child at a certain age, but not having their first sexual intercourse at that age or before.
} 
characteristics that also affect the woman's likelihood of postponing the establishment of a family.

Individuals who are more likely to continue further in their schooling are likely to be the same individuals who would have fewer children and possibly postpone marriage due to both a better innate understanding of personal health and possibly career ambition. This suggests that the negative relationship between schooling and the various outcomes could be driven by these omitted characteristics. In order to address this concern, I implement an instrumental variables strategy by exploiting the exogenous change in schooling due to the 1985 education reform in Kenya.

\section{b. Identification: The Estimated Likelihood of Being Treated By the 1985 Reform}

Students who completed the seventh year of primary school and passed the primary school exam by 1983 graduated with the certificate of primary education. During this time period primary education was not compulsory in Kenya, and students could begin school at age six. However, in 1978 less than half of the students enrolled in grade one were six years old (Somerset, 2007). Students entering school at later ages and high repetition rates means that the effects of the reform were dispersed across the transition cohorts, as seen in Figure 2 and Figure 3. Following the concept from Angrist and Lavy (1999), I construct an instrument that predicts the probability that an individual from birth cohort $c$ is affected by the 1985 reform. Similar to Borkum (2010), I use pre-reform data on grade-one enrollees to predict the probability that an individual born in a specific year and quarter was faced with an eighth year of primary school in order to receive a certificate. ${ }^{8}$ In addition to the age of students enrolled in grade-one, I use data on enrollment and repetition at every grade of primary school, and transition from the last year of primary school to secondary school to predict the likelihood of treatment.

Using this pre-reform data allows me to take into account large increases in primary school enrollment in the 1970s. As documented by Somerset (2007, 2009), the removal of primary schooling fees in the pre-reform period led to large increases in the number of students that entered the first year of

\footnotetext{
${ }^{8}$ Information regarding the age of grade one enrollees is only available for 1978 and 1979 (Somerset, 2007). I use available population data and gross enrollment ratios to back out cohort size, and estimate the age of grade one enrollees for the remaining cohorts.
} 
primary school. These fee reductions also led to increased dropout rates in the early grades of primary school, although some of the enrollment effect persisted through the later grade levels leading to an increase in primary school completion and secondary school enrollment.

The instrument is defined as one minus the probability that an individual born in a given year and quarter advances to the first year of secondary school no later than 1984. Students who entered secondary school in 1984 or before were not affected by the extension of primary school. However, students who did not matriculate to secondary school prior to 1985 faced eight years of primary education. The instrument can be represented by the following equation:

$$
\text { Inst }_{c}=\left\{\begin{array}{l}
1 \quad \text { if } c \geq 1972 \mathrm{Q} 1 \\
\operatorname{Pr}(\text { Treated })=1-\operatorname{Pr}(\text { Secondary School before 1985) } \quad \text { if 1964Q4 }<c<1972 \mathrm{Q} 1 \\
0 \quad \text { if } c \leq 1964 \mathrm{Q} 4
\end{array}\right.
$$

The instrument is equal to one for individuals born in 1972 and later. The probability of being treated is assumed to be zero if born in 1964 or before. ${ }^{9}$

The probability of reaching secondary school before 1985 for a woman in birth cohort $c$, with birth year by, is defined by the equation

$$
\begin{aligned}
& \operatorname{Pr}(\text { Secondary School before } 1985)= \\
& \sum_{A=6}^{1977-b y} \sum_{r=0}^{1971-A-b y} \operatorname{Pr}(\text { Start School }=A \mid c) \operatorname{Pr}(\text { Complete Primary } \mid \text { repeat }=r) .
\end{aligned}
$$

The right hand side of this equation is equal to the probability of starting school at age $A$ multiplied by the probability of completing primary school, summed over the range of ages at which one could start school and number of grades one could repeat while still graduating to secondary school before 1985 . For example, if a student was born in 1970 she could start school at either the age of six or seven, repeat one

\footnotetext{
${ }^{9}$ The results are not dependent on this assumption. Adjusting the transition period length yields similar estimates.
} 
grade if starting at six, and still advance to secondary school before the reform. ${ }^{10}$ The probability of starting school at age $A$ depends on the individual's birth cohort (year and quarter). Children born in the first quarter of each year are more likely to start school in their age six year, and the likelihood of entering school at this age becomes progressively lower for each of the following quarters. Also note that the model does not account for dropout. For this reason the model estimates that the probability of reaching secondary school prior to the reform moves closer to one for earliest cohorts in the transition period.

The value of the instrument across cohorts is shown in Figure 6. The instrument is plotted using the solid shapes and ranges from 0 to 1 . Figure 6 also includes the fraction of students whose highest grade completed is the eighth grade in primary school, from Figure 2. Across the pre-reform, transition, and post-reform periods the instrument closely follows the pattern from Figure 2, indicating its success in predicting the likelihood that a woman, from a given birth year and quarter, was affected by the 1985 restructuring of the education system.

\section{c. The Reduced-Form and 2SLS Model}

I verify that the instrument predicts the change in education, the endogenous variable in the OLS model. This first stage relationship can be described by the following equation:

$$
\begin{aligned}
& \operatorname{yrschl}_{i c}= \\
& \alpha_{F}+\operatorname{Inst}_{c} \beta_{F}+\sum_{p=1}^{3} \operatorname{age}_{i c}^{p} \pi_{F p}+\sum_{n=1}^{2} \operatorname{qtrend}_{c}^{n} \varphi_{F n}+X_{i c} \theta_{F}+\varepsilon_{F i c} .
\end{aligned}
$$

The variable $I n s t_{c}$ is the instrument described in equations (4) and (5). The $F$ subscript on the parameters denotes that the parameters are estimated in the first stage equation, all covariates are the same as described in the OLS model, equation (3). Acknowledging the drawbacks of each education measure, I

\footnotetext{
${ }^{10}$ For simplicity, it is assumed that if an individual completes seven years of school that they will enter secondary school, and that the probability of repetition at any grade is independent from past history and is only defined as a given cohort's probability of matriculating to the next grade. A student could fail any grade (1 to 7). If a student fails second grade, for example, it is assumed that she will then join the following cohort's second grade class and obtain their probability to matriculate to the next grade. The number of permutations of a student's path to secondary school expands rapidly as the number of possible "failures" increases.
} 
estimate the first stage equation across all three measures of education, years of schooling $\left(y r s c h l_{i c}\right)$, and the Atleast 8 and Education 8 variables, to ensure that the findings are not unique to a single measure.

In Table 4, I present the estimates of $\beta_{F}$ using all three measures of education. All estimates in Table 4 show that the instrument predicts statistically significant increases in education due to the reform, with large F-statistics across all measures of education. In column (1), the reform is estimated to increase schooling by 0.74 years, a ten percent increase based on the sample mean. The magnitude of this result coincides with the expectation that the one year increase in schooling for treated individuals is lessened due to attrition from requiring an extra year to complete primary school. The model also estimates a 23.3 percentage point increase in the fraction of women completing at least eight years of school, and a 27.4 percentage point increase in the fraction of women ending their education after eight years of primary school.

Due to the fact that each measure of education does not perfectly capture the full impact of the 1985 reform, I mainly focus on the estimates from the reduced-form model. In this model, the outcome of interest, such as intercourse, marriage, or fertility, is regressed on the instrument itself.

$$
y_{i c}=\alpha_{R}+\operatorname{Inst}_{c} \beta_{R}+\sum_{p=1}^{3} a g e_{i c}^{p} \pi_{R p}+\sum_{n=1}^{2} q \operatorname{trend}_{c}^{n} \varphi_{R n}+X_{i c} \theta_{R}+\varepsilon_{R i c}
$$

The main focus of the following section of the paper will be on the estimates of $\beta_{R}$, which represents the estimated effect of the reform on a selected outcome. Although the 1985 reform increased schooling by one year for students who are primary completers, secondary completers, or between, the extension of primary school may have also led to increased attrition, yielding an effect of the reform similar to those estimated in the first column of Table 4. The estimated effect of the reform is important, but the effect of a year of schooling may be of more general interest. The impact of an additional year of schooling is likely greater than the point estimate of $\beta_{R}$. This is because the first stage result is less than one. When estimating the effect of a year of schooling using a 2SLS model, with the instrument predicting years of 
schooling, the coefficient of interest would be equal to the reduced-form effect of the instrument $\left(\beta_{R}\right)$ over the first stage effect $\left(\beta_{F}\right)$.

\section{Results}

\section{a. Baseline Reduced-Form Results}

In Table 5, I report the reduced-form results for each age from 15 to 25, using the same four outcomes examined in Table 3: first intercourse, marriage, and birth, along with total fertility. ${ }^{11}$ Each point estimate is generated from a separate regression. The results in Panel A, for first intercourse, are not statistically significant until the later ages, from 23 to 25 . For these ages, the model estimates that the reform led to a three to four percentage point decline in the likelihood of a woman becoming sexually active. This could be partially driven by a reduction in pre-marital sex at these same ages of about two percentage points; however, the reductions in pre-marital sex alone are not statistically significant. In Panel B, for marriage, the results are negative and statistically significant at the 99 percent confidence level beginning at age 18 . The estimates indicate that the reform led to women being 6.2 percentage points less likely to be married by the age of 18, and the estimates remain similar through the age of 21 . These results suggest that women are postponing marriage from their late teens to early twenties. The estimated effect on marriage remains slightly negative, although smaller in magnitude, through the age of 25. The results for age at first birth, reported in Panel C, establish a similar pattern. Trailing the dip in the marriage results, the estimated effect of the reform on the likelihood that a woman has given birth by age 19 is statistically significant at the 95 percent confidence level. The result then increases in both magnitude and significance, estimating that the reform led to an 8.4 percentage point reduction in the likelihood of a woman giving birth by age 20 . The estimated effect becomes slightly less negative as women move into their twenties. The effect of delaying a women's first birth lags the effect on marriage by between one and two years, suggesting that the effect on first birth may be related to women delaying

\footnotetext{
${ }^{11}$ I also estimate the effects between ages 11 and 14; there are no large or statistically significant results for those ages. The results are robust to excluding respondents 25 years old and younger in all regressions.
} 
marriage. However, the estimated effect on first birth is larger in absolute value than the effect on marriage for the ages from 22 to 25 . Although the reduction in marriage may play a role in delaying childbearing, it cannot explain the entire result. It is at these later ages the reform leads to postponed sexual activity, possibly explaining some of the more persistent effect seen in Panel C. Furthermore, there is also evidence that the reform increased the likelihood of women in their twenties becoming sexually active or married and waiting to have their first child. This suggests that increased schooling may also have led to other changes in behavior.

Beyond the postponement of women's initial fertility, the results in Panel D show the evolution of the reform's effect on total fertility across different ages. At age 20, the results show that the reform led to a statistically significant reduction of 0.113 births. The results in Panel D demonstrate that the effect becomes increasingly negative for women in their twenties. By age 25 , the reform led to a reduction of 0.324 births, a result that is statistically significant at the 99 percent confidence level. Although a woman's fertility is not complete at this age, in results not shown, there is no evidence of a reduction in birth spacing between a woman's first few births. The results in Panel D reveal two insights. First, as with Panel C, these results show that the effect of the reform persists beyond the ages of school enrollment. Second, the magnitude of the result on total fertility is increasing for women in their twenties, providing evidence the effect is not driven solely by an incarceration effect. This is evidence that the human capital accrued by women with higher levels of schooling plays an important role in reducing fertility rates, even into the woman's mid-twenties.

\section{b. Robustness: Controlling for Enrollment and an Alternative Instrument}

The instrument is assigned based on an individual's quarter and year of birth, and calculated using pre-reform enrollment data. This instrument is valid if the reform only affects the outcomes of interest through its effect on schooling. The reduced-form estimates for fertility will be biased if the instrument is capturing a secular trend in women's propensity to attend and advance through primary 
school. It is, however, unlikely that the instrument is measuring some unobserved endogenous change in the demand for beginning secondary school before 1985, an arbitrary point in time.

I address this issue in two ways. First, in one set of auxiliary regressions, I include a control for total grade one enrollment for each cohort's age six year. The results with the inclusion of a control for grade one enrollment in a cohort's age six year are shown in Table 6. The results demonstrate a nearly identical pattern to the baseline results. The reform's effect on marriage is largest for the ages 18 to 21 , as it was without the enrollment control; the pattern in Panel A also mirrors closely the results from the baseline estimates in Table 5. The estimates for first birth again lag that of marriage. The estimates for total fertility also remain similar to the baseline results, but increase slightly in magnitude. The results in Table 6 suggest that the large fluctuations in enrollment during the 1970's are not driving the results.

Second, endogenous changes in enrollment could also be affecting the calculation of the instrument, which is constructed using cohort-level enrollment data. The instrument used in the baseline estimates was constructed using enrollment data for the transition period cohorts to calculate a probability of treatment. However, there could be a concern that some underlying characteristics of the cohorts are different, and this may lead to members of certain cohorts to endogenously be more or less likely to advance to secondary school by 1985 . This trait would be captured in the estimation of the original instrument, leading to biased estimates. To remove this potential issue, I estimate an alternative instrument only using three pieces of information. First, I use the age of grade one school attendees from the 1989 Kenyan census. This information, which is from the post-reform period, avoids any concern of changes in children's propensity to enroll in school in the pre-reform period affecting the construction of the instrument. Next, I use a consistent 40 percent transition rate from the last year of primary school to secondary school. This is the average of the transition period. Finally, I use a Bernoulli distribution to calculate the probability of advancing to the next grade. I choose a 90 percent success rate for all grades and years, and then scale the estimates to equal zero in 1964 to match the original transition period. The F-statistic for the alternative instrument in the first stage is actually larger for the years of schooling variable, and smaller, but still greater than 80 , for both the AtLeast 8 and Education 8 variables. 
Using the alternative instrument I rerun the model using equation (7); the results are presented in Table 7. The largest difference from the results seen in the previous two tables is the increased significance of the estimates in Panel A, for age at first intercourse. The point estimates for the first intercourse outcome dips prior to the estimated effects for the other outcomes, at the ages 16 and 17 , before becoming statistically significant at age 18 . The estimates in the other three panels are very similar to those seen previously. The results in Table 7 are robust to the inclusion of the enrollment control.

I can also use the same two methods to construct instruments that vary only by annual birth cohorts, instead of quarterly cohorts. I then re-estimate the results clustering the standard errors at the annual birth cohort level. The results remain robust whether the annual instrument was calculated using enrollment data or the Bernoulli probabilities of advancement.

Due to the DHS limiting their data collection to women under 50, the density of observations is smaller for the older cohorts in the sample. However, the pattern seen in the results up to this point are robust to removing the early cohorts from the sample, with or without the control for grade one enrollment. Also, when restricting the sample to include only cohorts born in 1955 or later, the estimates remain similar in both magnitude and significance to the results from the previous tables.

The results are also robust to the use of alternate time trends. The baseline model uses a quadratic time trend across birth quarter; the results remain robust when using a linear trend. An alternative approach would be to assign each of the three time periods a separate time trend, pre-reform, transition, and post- reform. When I do this, the results are robust to this three-part trend being included as either a linear, quadratic, or cubic polynomial. ${ }^{12}$

\section{c. Placebo Tests: Results for Non-Treated Respondents}

Even though the reduced-form model outlined in equation (7) includes time trends, it is possible that there remains some type of change in Kenya over this time period that led to reduced levels of

\footnotetext{
${ }^{12}$ Equations for the three-part time trend are included in the appendix, along with results for the discussed robustness checks.
} 
fertility. Therefore, to insure there is not an unobserved fertility trend in Kenya that is driving these results, I conduct a pair of placebo tests to estimate the effect of the reform on women whose level of schooling should not have been changed by the reform. ${ }^{13}$

The reduced-form results outlined above indicate that cohorts impacted by the 1985 reform had lower fertility and marriage rates while the first-stage results suggest that these cohorts also had more years of schooling. The reform should have no effect on outcomes for women who left primary school well before the seventh year since their behavior is not impacted by the reform. In contrast, if there is a secular change in fertility for all women in Kenya, we would expect even women with few years of schooling to have reduced fertility over time. To test this, I re-estimate the reduced-form results for all individuals who completed less than five years of school, these results are displayed in Table 8. Of the 44 point estimates, there is not a single statistically significant estimate. More importantly, none of the four panels demonstrate a pattern similar to those seen in the previous estimates. This evidence strongly suggests that the robust set of results seen up to this point is not due to some secular trend affecting all Kenyans over this time period.

I repeat this placebo exercise for college attendees. The reform's effect on these women is ambiguous, due to the pre-reform education structure's inclusion of "upper secondary" school. However, a college graduate under either education system is in school for the same number of years, $16 .{ }^{14}$

Estimating the model for women who at least attended college yields results, shown in Table 9, similar to those for women with less than five years of school. Again, the results show little significance, and there is no evidence of the patterns seen in the previous tables. These estimates emphasize the fact that the result is concentrated with the individuals whose schooling is increased by the reform. Individuals who would have obtained more or less schooling, regardless of the education reform, show no signs of altered

\footnotetext{
${ }^{13}$ These placebo tests are done under the assumption that changing the length of primary school did not have an effect on the demand for education.

${ }^{14}$ The pre-reform system consisted of $7+4+2+3$ years of school for a college graduate. The post-reform system is comprised of $8+4+4$ years of school.
} 
behavior, suggesting that there is no secular trend in the data contaminating the basic reduced-form results. $^{15}$

\section{d. Exploration of Potential Mechanisms}

In addition to the reform's effect on the beginning of sexual activity, marriage, and childbearing discussed in the prior sections, additional mechanisms could provide further insight into the link between schooling and fertility. I begin by further investigating the possibility that the incarceration effect has played a role in reducing fertility, and I find no relationship between the conditional likelihood of completing secondary school and the magnitude of the reform's effect on either fertility or marriage. This suggests that an incarceration effect is not playing a large role in the reductions in marriage and fertility seen in the previous subsections. If there was a significant incarceration effect behind the reductions in these outcomes, the reform's effect should be stronger for populations more likely to receive their extra year in school at an older age, when they are more likely to be sexual active and participating in the marriage market. ${ }^{16}$ I examine this relationship by first calculating the fraction of women who have completed four years of secondary school for ethnicity/type of childhood residence groups, using data from women who were older than 25 in the 1989 round of the DHS. Therefore, all of the data used in this calculation are taken from women in pre-reform cohorts. In Figure 7, for each ethnicity/type of childhood residence group, I plot the fraction of women who completed four years of secondary school against the estimated effect of the reform. The effect is estimated by rerunning the reduced-form model for each group. In the left panel, I plot the effect on total fertility at the age of 25 in Figure 7 a, total fertility at age 21 in Figure 7b, and the effect on marriage at each of these ages in the right panel. A regression line weighted by the number of observations in each group is included in each graph. There is no consistent or

\footnotetext{
${ }^{15}$ When the model is estimated for only women who completed between 7 years of primary school and 4 years of secondary school all of the results from Tables 5 to 7 hold.

${ }^{16}$ At age 14 only 15 percent of women have had intercourse, seven percent are married, and four percent have had their first child. By age 18, the age when students complete secondary school if they graduate on time, all three of these measures increase dramatically, 70 percent of women have had intercourse, 40 percent are married, and 40 percent have given birth to their first child.
} 
significant negative relationship between the outcomes of interest and the likelihood of completing secondary school, demonstrating that the incarceration effect is not likely driving the results. Furthermore, this analysis reveals a fair amount of heterogeneity in the reform's effect that exists within demographic groups, and even for women with similar education levels. This underscores the importance of examining the relationship between schooling and fertility as part of a large scale reform.

Previous work has also studied the relationship between education and access to information (Thomas, Straus, Henriques, 1991); increases in education may lead women to better understand healthcare options available to them. A potential consequence of this could be an increase in abortions, which may have contributed to the reduction in fertility. The DHS classifies any pregnancy not ending in a live birth a termination, but an increase in the use of abortion to avoid having a child would still lead to an increase in recorded terminations. ${ }^{17}$ The result in Table 10's first column demonstrates that the increased education generated by Kenya's policy change did not lead to more respondents reporting having ever having a terminated pregnancy.

There is also no evidence that changes in the husband's characteristics played a role in reducing fertility. Due to assortative matching it could be expected that women affected by the reform, may have married men with more desirable characteristics, leading households to make different decisions regarding fertility. However, there is no evidence that these women married different types of men. Estimates in the second and third columns of Table 10 demonstrate that women are marrying men with the same level of education and that the reform did not affect the age difference between husband and wife. On average, the husband is nearly seven years older than his wife. This means that the husbands of women affected by the reform are unlikely to have the same mechanical increase in their education, as shown in column (2). This leads to the expected result that, although women in this sample marry the same type of men, they reduce the marital education gap between husband and wife by 0.441 years of school. The average marital education gap in the sample is about 1.2 years of schooling; the reform

${ }^{17}$ Although abortions in Kenya are illegal, 11 percent of the sample reported ever having a pregnancy terminated. 
reduced this gap by just over one-third. ${ }^{18}$ These results provide evidence that the fertility decline was not driven by changes in the husband's characteristics, but that women may have increased their ability to make their own personal decisions due to the large reduction in the marital education gap. This increased empowerment is likely essential to women's ability to reduce fertility if so desired.

Throughout Kenya, knowledge of modern contraception is extremely high. Across all birth cohorts, levels of education, and waves of the DHS survey roughly 90 to 95 percent of women report having knowledge of modern contraceptive methods. This is likely due to coordinated efforts between the international community and the Kenyan government to promote health and family planning throughout the country. This effort began in 1974 with two programs from the Kenyan Ministry of Health to establish a rural network of health facilities and training schools (World Bank, 1992). ${ }^{19}$ However, even with near universal levels of contraception knowledge, the Kenyan family planning programs were considered a failure through the mid-1980s, having a negligible impact on population growth and fertility (World Bank, 1992; Heisel, 2007). It was not until the 1989 that clear evidence of a fertility decline in Kenya began to emerge. Between 1977 and 1984 the fertility rate in Kenya declined less than 3 percent. However, between 1984 and 1989, the time of the education reform studied in this paper, fertility declined 13 percent (World Bank, 1992).

The timing of the decline in fertility aligns with the implementation of the 1985 education reform. However, if the education reform was the driver of the decline in fertility seen in the late 1980s, women affected by the reform should have the largest reductions in fertility over this time period. To verify this is the case, I use the 1989 wave of the DHS and the 1977/1978 wave of the precursor to the DHS, the World Fertility Survey. Using these two surveys I compare the average number of births for women at a given age in 1989 to the average number of births for women at the same age in the 1977/1978 survey. In

\footnotetext{
${ }^{18}$ The reform also led to a smaller increase in education for men born between in 1950 and 1980 . This suggests that the reform will continue to reduce the marital education gap for women in later cohorts; the expected reduction for these women will be over half the magnitude of the results seen in Table 10.

${ }^{19}$ In the 1989 DHS Survey over 95 percent of pre-reform women reported having knowledge of modern contraceptives. This suggests that these early programs were successful in educating women regarding available modern contraceptive methods.
} 
Figure 8, I plot the percentage change in number of births from 1977 to 1989 for each age. As expected, the largest declines in fertility are consistently for women more likely to be affected by the reform. Women aged 15 to 17 in 1989 were part of the post-reform cohorts, and those between 18 and 24 years old in 1989 were members of the transition cohorts. Three of the four largest reductions in fertility are from the post-reform cohorts, and the post-reform and transition cohorts generate ten of the fourteen largest declines in fertility between 1977 and 1989. Although, the family planning efforts in Kenya were successful in disseminating information related to family planning and contraception, and likely increased access, it was not until after the 1985 education reform that fertility levels in Kenya began to fall.

Ashraf, Field, and Lee (2010) found that the availability and use of contraception was only effective in reducing unwanted pregnancies for Zambian women when they were randomly assigned to independently make the decision to use contraception and what type of contraception to use. The significant reduction of the marital education gap seen in Table 10 may have had the effect of endowing women with greater empowerment over their personal decision making. Furthermore, the increase in education also likely increased women's relative earning potential, which could have positively affected bargaining power in the household decision process. Evidence of this increased empowerment can be seen in Table 11. These results show that the reform led to an increased likelihood of women using modern contraception before having their first child. Panel A uses the alternative cubic three-part time trend discussed in the previous section, and Panel B uses the baseline's quadratic quarterly time trend. ${ }^{20}$ The first column estimates the effect of the reform using the full sample. The results in both panels suggest that the reform led to a statistically significant increase in the likelihood of early contraception use. The model is then estimated separately for the two placebo groups of women, columns (2) and (3), and women whose level of schooling was most affected by the reform, in column (4). The fourth column includes women from all cohorts who completed between seven years of primary school and four years of secondary school. In Table 11, the effect is both larger in magnitude and statistically significant only for 
the estimates which include women with treated levels of education, the first and fourth columns. Instead of randomly being assigned to have the option to independently make their contraception decision, the higher level of schooling generated by the policy reform has increased these women's ability to independently make that decision. As further evidence of the reform's effect on the empowerment of these women, the results in Table 12 show that the reform led to increases in the likelihood of being tested for HIV/AIDS.

This evidence suggests that information and preferences alone may not be enough to change fertility outcomes. In addition to the postponement in marriage and sexual activity seen in Table 5, increasing women's empowerment and their ability to independently make decisions related to contraception is essential to reducing fertility rates in developing parts of the world.

\section{e. 2SLS Estimates Using Years of Schooling}

As documented earlier, there is a concern with measuring years of schooling for women in transition cohorts who progress beyond primary school. Due to the measurement error in the years of schooling variable, the estimates in this section should be analyzed with caution. However, it would be useful to calculate the 2SLS estimates using years of schooling to compare the magnitude of the estimates from this paper with those found in the literature.

Using the years of schooling variable, with the first stage described in equation (6), the secondstage equation can be described as follows:

$$
y_{i c}=\alpha_{F}+\widehat{y r s c h} l_{c} \beta_{S}+\sum_{p=1}^{3} a g e_{i c}^{p} \pi_{S p}+\sum_{n=1}^{2} q \operatorname{trend}_{c}^{n} \varphi_{S n}+X_{i c} \theta_{S}+\varepsilon_{S i c}
$$

All variables are defined the same way as previous equations. I estimate the second stage equation on the same four main outcomes seen throughout this section, age at first intercourse, first marriage, first birth, and total fertility. To illustrate the estimated effect of an additional year of education, I estimate the model for each age, as was done with the baseline results, and plot the point estimates of $\beta_{S}$ in the Figures 9a through 9d, along with the 90 percent confidence intervals. 
The results for first intercourse, Figure 9a, show a consistently negative estimate that is statistically significant for the ages from 23 to 25 . For the effect on marriage, the strong negative effect for the ages 18 to 21 seen in the reduced-form is now visible in Figure 9b, as is the persistence of the reduction in marriage. The estimated ten percentage point reduction for these ages is large. Only 40 percent of 18-year-old women in the sample are married; the fraction increases to 67 percent for 21 -yearold women. The effect on marriage shows a sharp reversion towards zero at age 22, but the point estimates remain consistently below zero. The effect for first birth, Figure 9c, finds its lowest point at age 20 and remains negative through the age of 25. Most prominently, the effect of an extra year of schooling on total fertility continues to become increasingly negative for older women, Figure $9 \mathrm{~d}$. The one year increase in schooling is estimated to decrease fertility for women by nearly one-half of a birth, at the age of 25 .

\section{Conclusion}

The results from this paper show that education structure could be a significant policy lever for governments to employ in their effort to promote education. The increase in schooling, driven by the 1985 Kenyan reform, is also shown to greatly impact a woman's fertility decision. It led to postponed marriage and sexual activity, and reduced levels of fertility. These results demonstrate the importance of education and the positive effect that increased schooling can have on the choices and decisions of young women.

The results for fertility demonstrate that the effect is not confined to the time period that women attend school, and becomes increasingly negative for women in their early twenties. This suggests, along with other evidence, that the incarceration effect is not driving the reduction in fertility. I am also able to rule out a number of additional mechanisms proposed by the literature. The results are likely not driven by changes in the likelihood that a woman ever had a pregnancy terminated, or changes in spousal characteristics. Furthermore, widespread knowledge of contraceptives alone seems unable to significantly affect fertility. The reform led to a reduction in the marital education gap, and increased early use of modern contraception. This evidence is consistent with the idea that an increase in schooling can lead to 
women having greater control over the household fertility decision, and ultimately, lower levels of fertility. 


\section{References}

Ainsworth, Martha, Kathleen Beegle, and Andrew Nyamete. 1996. "The Impact of Women's Schooling on Fertility and Contraceptive Use: A Study of Fourteen Sub-Saharan African Countries.” The World Bank Economic Review, 10(1): 85-122.

Angrist, Joshua D. and Victor Lavy. 1999. "Using Maimonides' Rule to Estimate the Effect of Class Size on Scholastic Achievement.” Quarterly Journal of Economics, 144(2): 533-575.

Ashraf, Nava, Erica Field and Jean Lee. 2010. "Household Bargaining and Excess Fertility: An Experimental Study in Zambia.” Working Paper, Harvard University.

Becker, Gary S. and H. Gregg Lewis. 1973. "On the Interaction between the Quantity and Quality of Children.” Journal of Political Economy, 81(2): S279-S288.

Becker, Gary S. 1993. Human capital: a theoretical and empirical analysis, with special reference to education, University of Chicago Press, Chicago, IL.

Black, Sandra E., Paul J. Devereux, and Kjell G. Salvanes. 2008. "Staying in the classroom and out of the maternity ward? The effect of compulsory schooling laws on teenage births." Economic Journal, 118(July): 983-1024.

Borkum, Evan. 2010. "Changing grade structure: Educational and labor market impacts in a developing country." Working Paper.

Breierova, Lucia and Esther Duflo. 2004. "The impact of education on fertility and child mortality: Do fathers really matter less than mothers?" NBER Working Paper No. 10513.

Duflo, Esther, Pascaline Dupas, and Michael Kremer. 2011. "Education, HIV, and Early Fertility: Experimental Evidence from Kenya." Working Paper.

Galor, Oded and David N. Weil. 1996. "The Gender Gap, Fertility, and Growth.” American Economic Review, 86(3): 374-387.

Hanusheck, Eric A. 1992. "The Trade-off between Child Quantity and Quality.” Journal of Political Economy, 100(1): 84-117.

Heisel, Donald F. 2007. "Family Planning in Kenya in the 1960s and 1970s." The Global Family Planning Revolution. Edited by Warren C. Robinson and John A. Ross. Washington D.C.: The World Bank.

Kenya Ministry of Education. 1986. "Country Report: Kenya. Development of Education 1984 to 1986." The Fortieth Session of the International Conference of Education, Geneva, Switzerland.

Kenya Ministry of Education. 1988. "Country Report: Kenya. Development of Education 1986 to 1988." The Forty-First Session of the International Conference of Education, Geneva, Switzerland.

Lam, David and Suzanne Duryea. 1999. "Effects of Schooling on Fertility, Labor Supply, and Investments in Children, with Evidence from Brazil.” Journal of Human Resources, 34(1): 160192. 
Lavy, Victor and Alexander Zablotsky. 2011. "Mother's schooling and fertility under low female labor force participation: Evidence from a Natural Experiment.” NBER Working Paper No. 16856.

La Ferrara, Eliana, Alberto Chong, and Suzanne Duryea. 2008. "Soap Operas and Fertility: Evidence from Brazil.” BREAD Working Paper No. 172.

McCrary, Justin and Heather Royer. 2011. "The Effect of Female Education on Fertility and Infant Health: Evidence from School Entry Policies Using Exact Date of Birth.” American Economic Review 101(1): 158-195.

Miller, Grant. 2010. "Contraception as Development? New Evidence from Family Planning in Colombia.” Economic Journal, 120 (June): 709-736.

Mocan, Naci and Colin Cannonier. 2012. "Empowering Women Through Education: Evidence from Sierra Leone." Working Paper.

Monstad, Karin, Carol Propper, and Kjell G. Salvanes. 2008. "Education and Fertility: Evidence from Natural Experiment.” Scandanavian Journal of Economics, 110(4): 827-852.

Munshi, Kaivan and Jacques Myaux. 2006. "Social norms and the fertility transition." Journal of Development Economics, 80(1): 1-38.

Nkinyangi, John A. 1982. "Access to Primary Education in Kenya: The Contradictions of Public Policy." Comparative Education Review, 26(2): 199-217.

O'Eiseman, Thomas. 1988. Benefiting from Basic Education, School Quality and Functional Literacy in Kenya. Pergamon Press, New York, NY.

Ohba, Asayo. 2009. "Does free secondary education enable the poor to gain access? A study from rural Kenya." CREATE Pathways to Access: Research Monograph No. 21.

Osili, Una Okonkwo and Bridget Terry Long. 2008. "Does female schooling reduce fertility? Evidence from Nigeria.” Journal of Development Economics, 87(1): 57-75.

Qian, Nancy. 2009. "Quantity and Quality and the One Child Policy: The Only-Child Disadvantage in School Enrollment in Rural China.” NBER Working Paper No. 14973.

Rasul, Imran. 2008. "Household bargaining over fertility: Theory and evidence from Malaysia." Journal of Development Economics, 86(2): 215-241.

Rharade, Abdelhag. 1997. "Educational Reform in Kenya.” Prospects, 27(1): 163-179.

Rosenzweig, Mark R. 1982. "Educational, Subsidy, Agricultural Development, and Fertility Change." Quarterly Journal of Economics, 97(1): 67-88.

Rosenzweig, Mark R. and Robert Evenson. 1977. "Fertility, Schooling, and the Economic Contribution of Children of Rural India: An Econometric Analysis.” Econometrica, 45(5): 1065-1079.

Rosenzweig, Mark R. and T. Paul Schultz. 1989. "Schooling, Information, and Nonmarket Productivity: Contraceptive Use and Its Effectiveness." International Economic Review, 30(2): 457-477. 
Schultz, T. Paul. 1994. "Human Capital, Family Planning, and Their Effects on Population Growth." American Economic Review, 84(2): 255-260.

Schultz, T. Paul. 1997. "Demand for children in low income countries." Handbook of Population and Family Economics. Edited by Mark R. Rosenzweig and Oded Stark. Amsterdamn: Elsevier.

Schultz, T. Paul. 2005. "Fertility and Income.” Economic Growth Center Discussion Paper No. 925.

Schultz, T. Paul. 2009. "How Does Family Planning Promote Development? Evidence from a Social Experiment in Matlab, Bangladesh, 1977-1996.” Working Paper, Yale University.

Schoumaker, Bruno. 2004. "Poverty and Fertility in sub-Saharan Africa: Evidence from 25 countries." Population Association of America Meeting, Boston, 2004.

Somerset, Anthony. 2007. "A Preliminary Note on Kenya Primary School Enrolment Trends over Four Decades.” CREATE Pathways to Access: Research Monograph No. 9.

Somerset, Anthony. 2009. "Universalising primary education in Kenya: the elusive goal." Comparative Education, 45(2): 233-250.

Tembon, Mercy and Lucia Fort. 2008. Girls' Education in the 21st Century: Gender Equality, Empowerment and Economic Growth. World Bank, Washington, DC.

Thomas, Duncan, John Strauss, and Maria-Helena Henriques. 1991. "How Does Mother's Education Affect Child Height?” Journal of Human Resources, 26(2): 183-211.

World Bank. 1992. "Population and the World Bank: Implications from Eight Case Studies." Washington D.C.: The World Bank. 
Figure 1 - 1985 School Reform

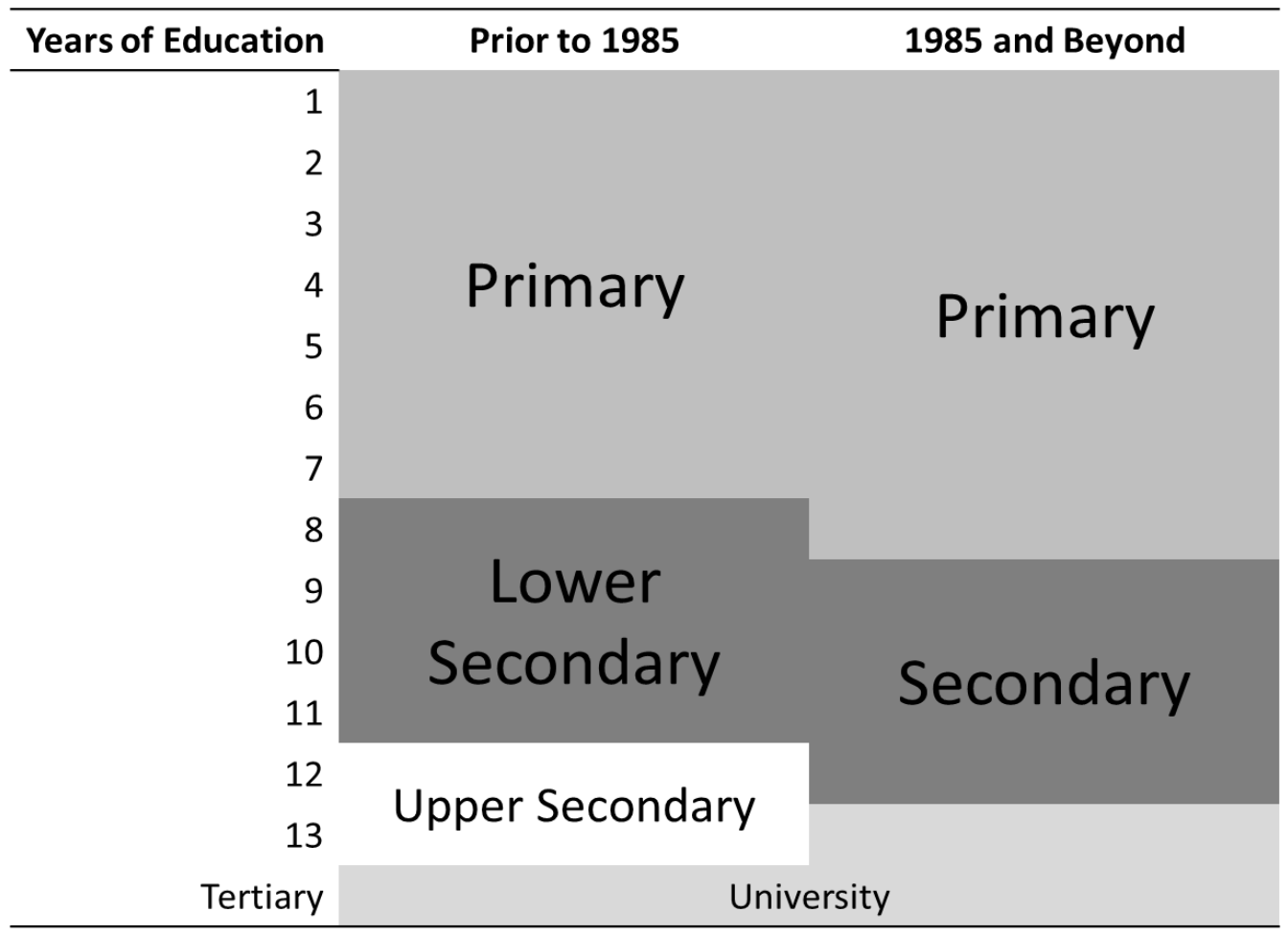

Figure 2 - Fraction of Women Whose Highest Level of Education is the Eighth Year of Primary School

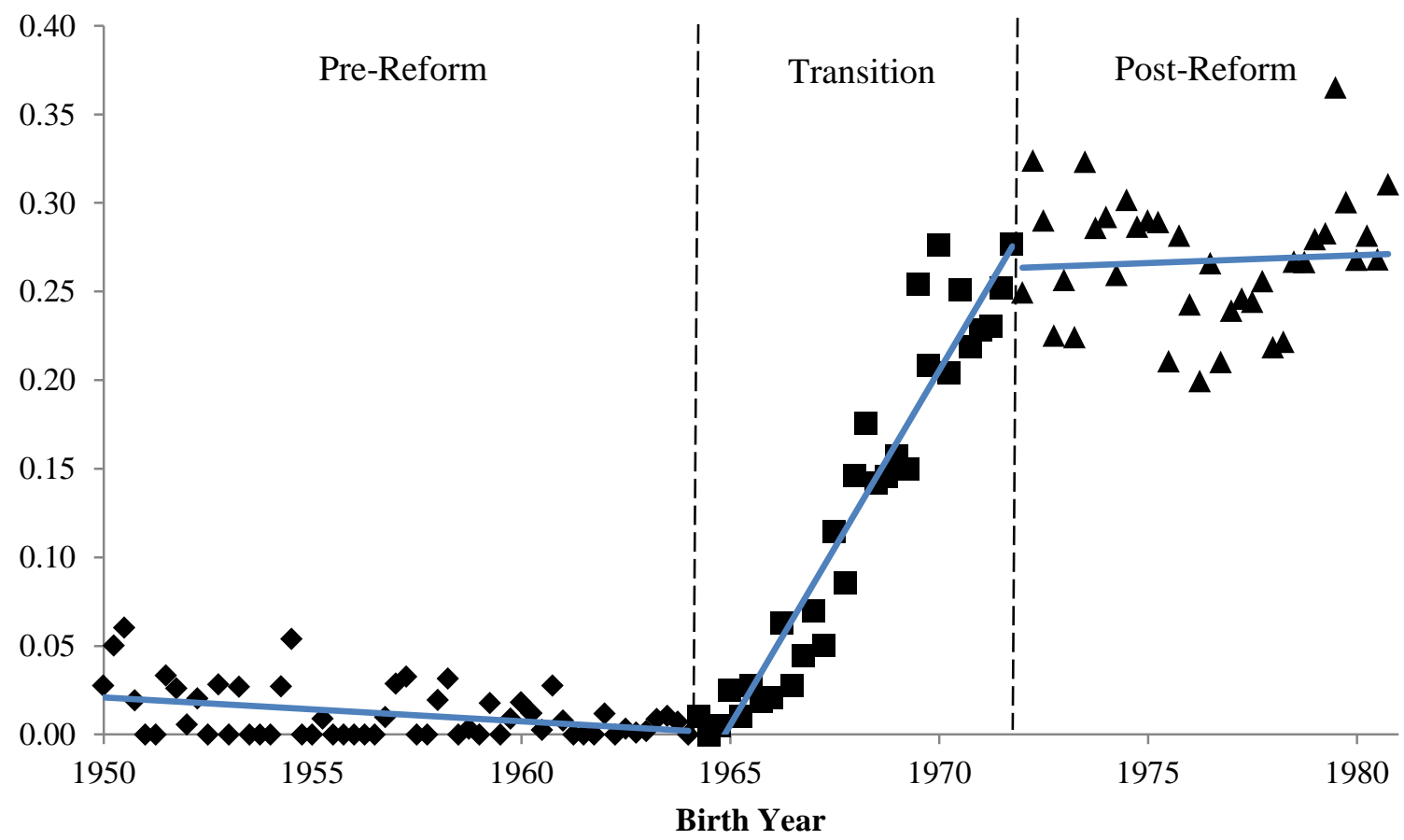




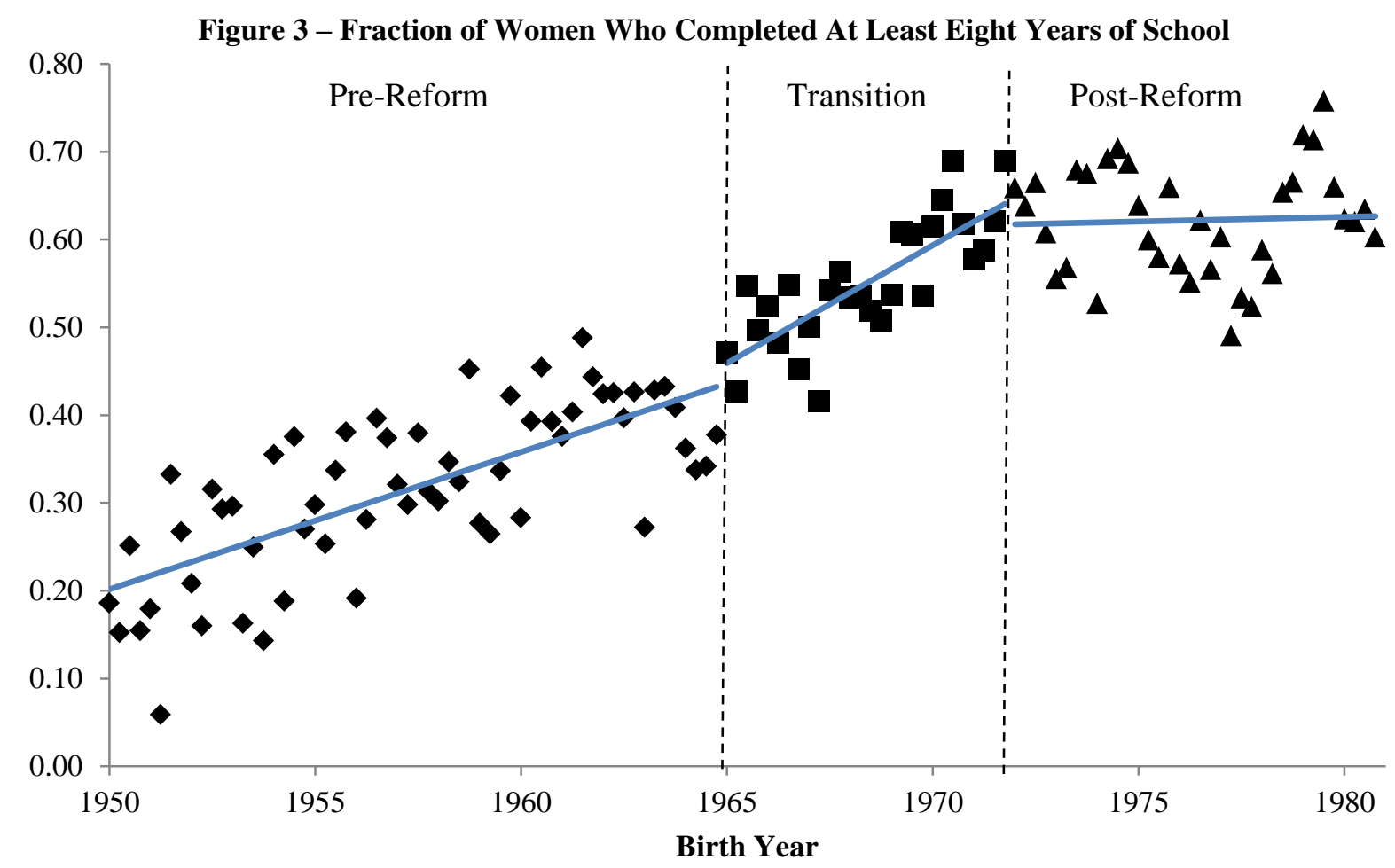

Figure 4 - Total Fertility at Age 25

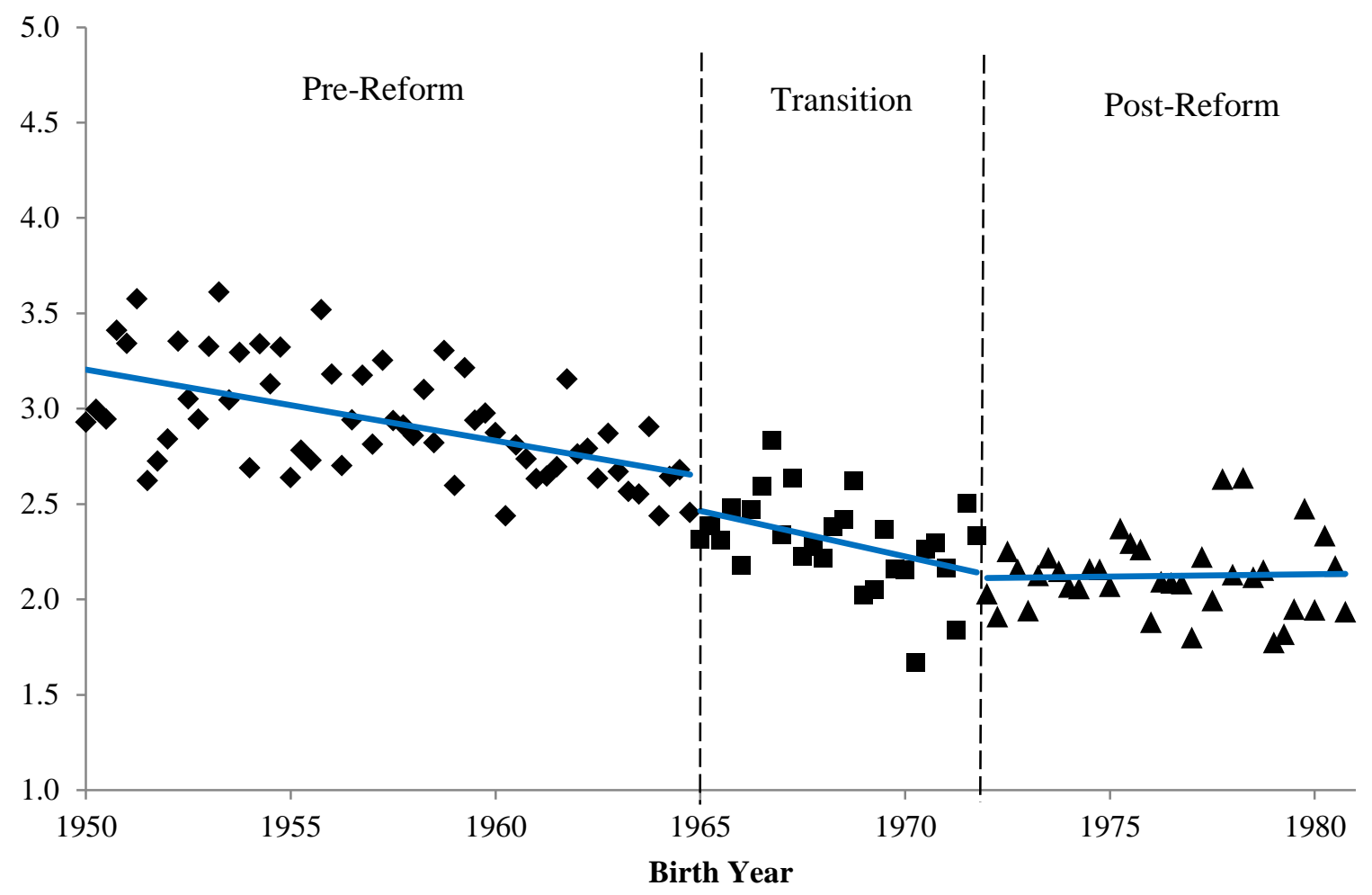


Figure 5 - Tanzania: Total Fertility at Age 25

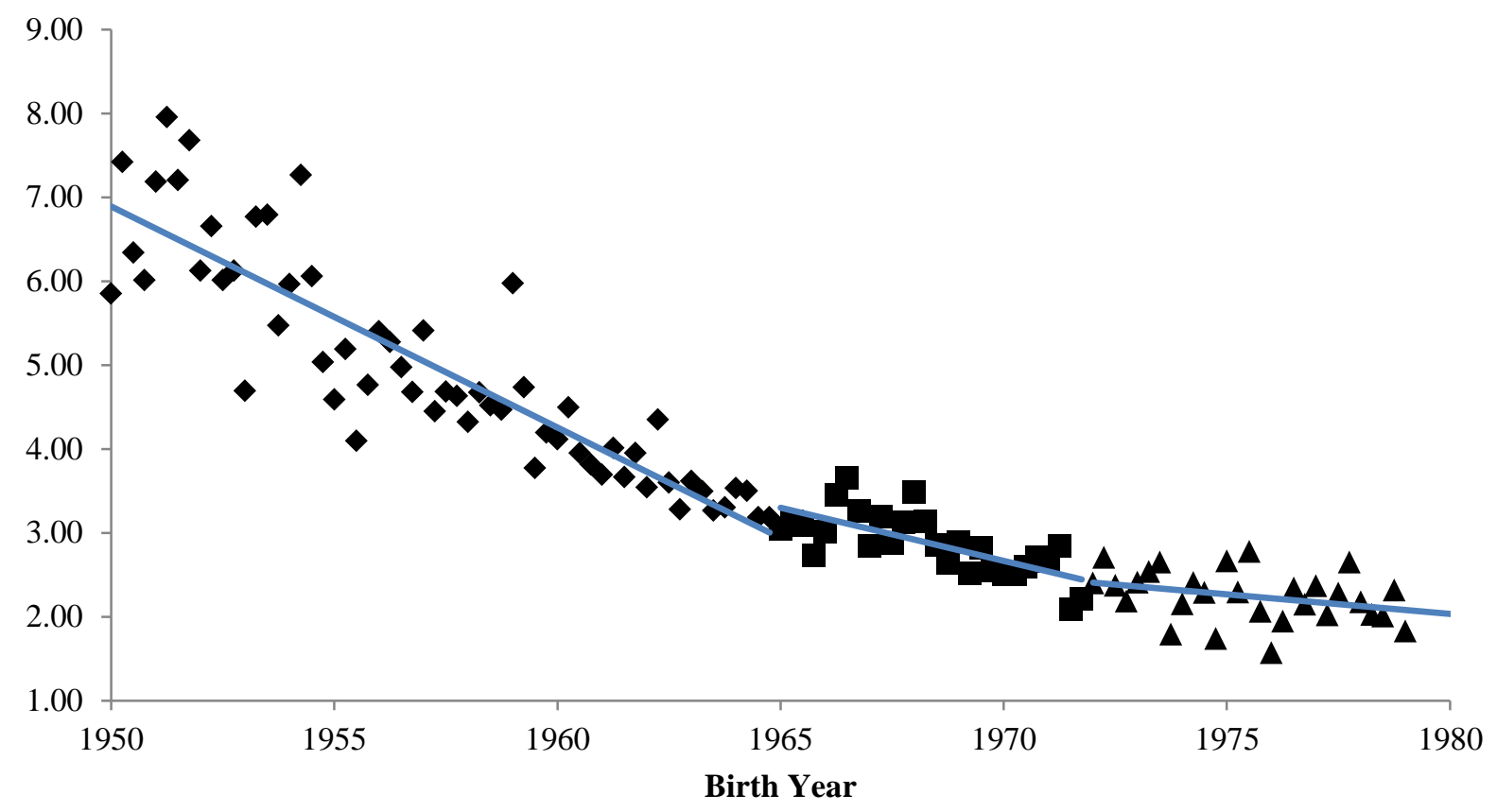

Figure 6 - Comparison of Highest Grade Completed is Eighth Grade (Xs) and the Instrument (solid shapes)

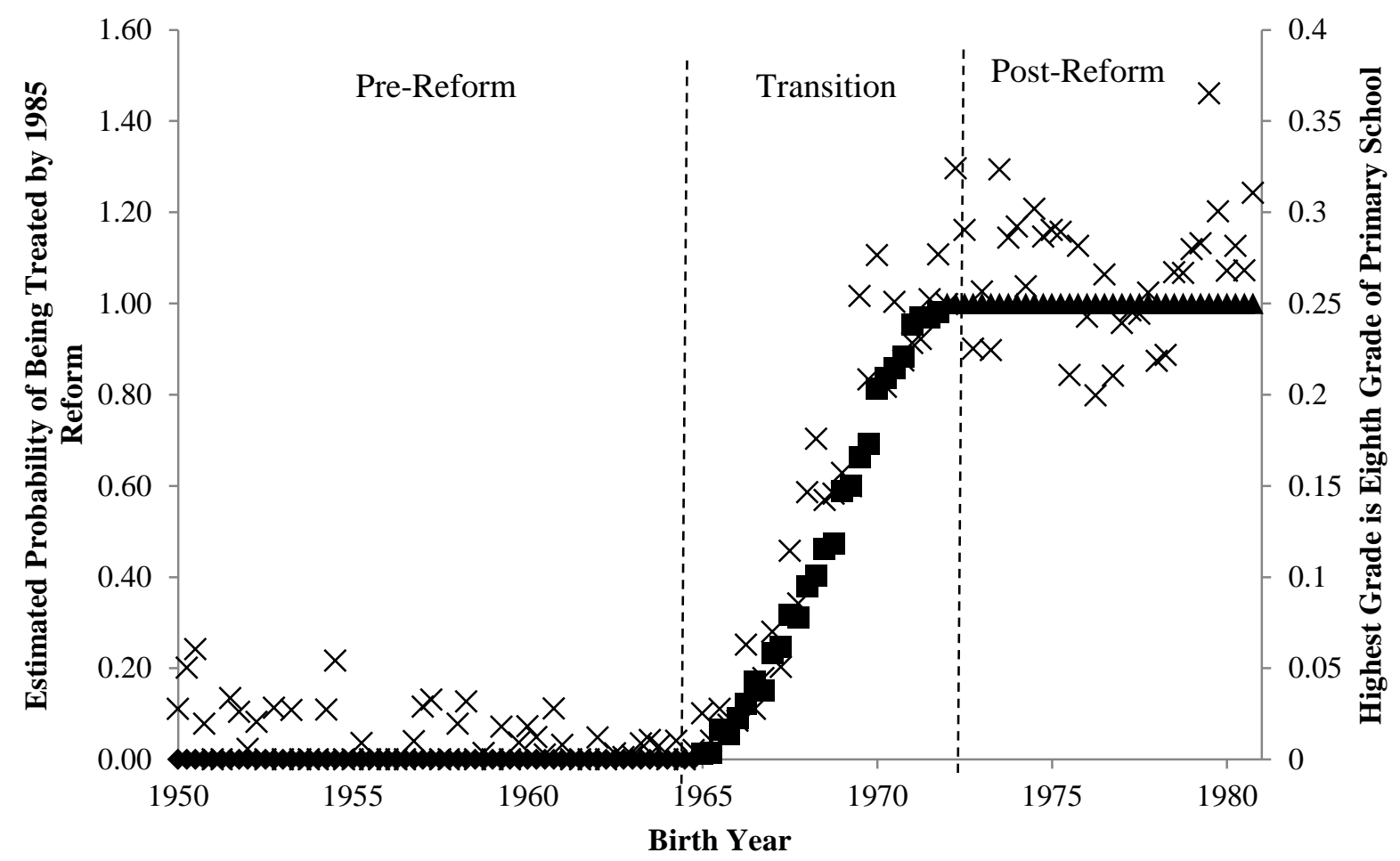


Figure 7a - Effect of Reform on Fertility and Marriage at 25 by Fraction Completed Secondary School (Ethnicity and Childhood Type of Residence groups using DHS)
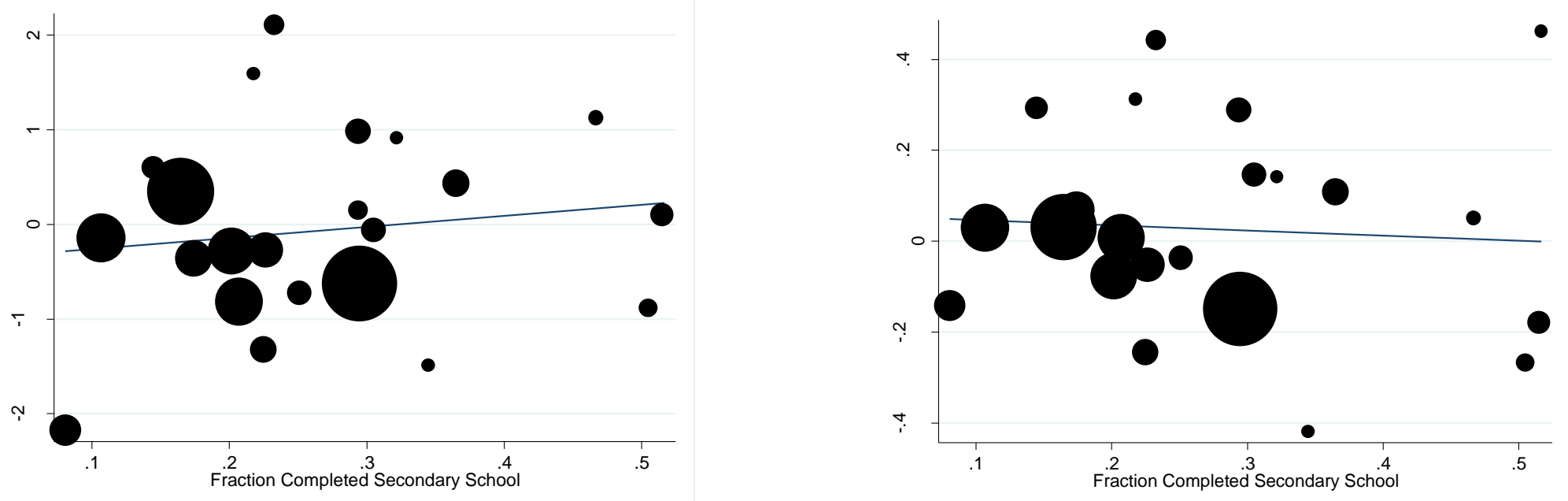

Figure 7b - Effect of Reform on Fertility and Marriage at 21 by Fraction Completed Secondary School (Ethnicity and Childhood Type of Residence groups using DHS)
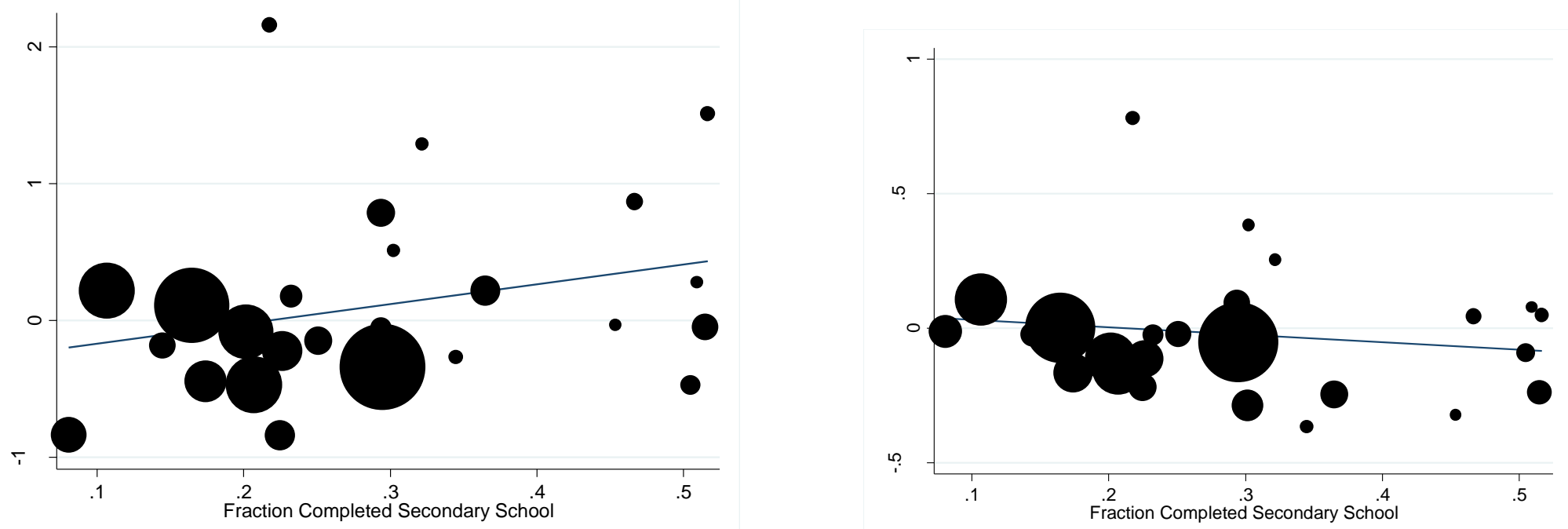
Figure 8 - Percentage Change in Total Fertility between 1977 and 1989, by age

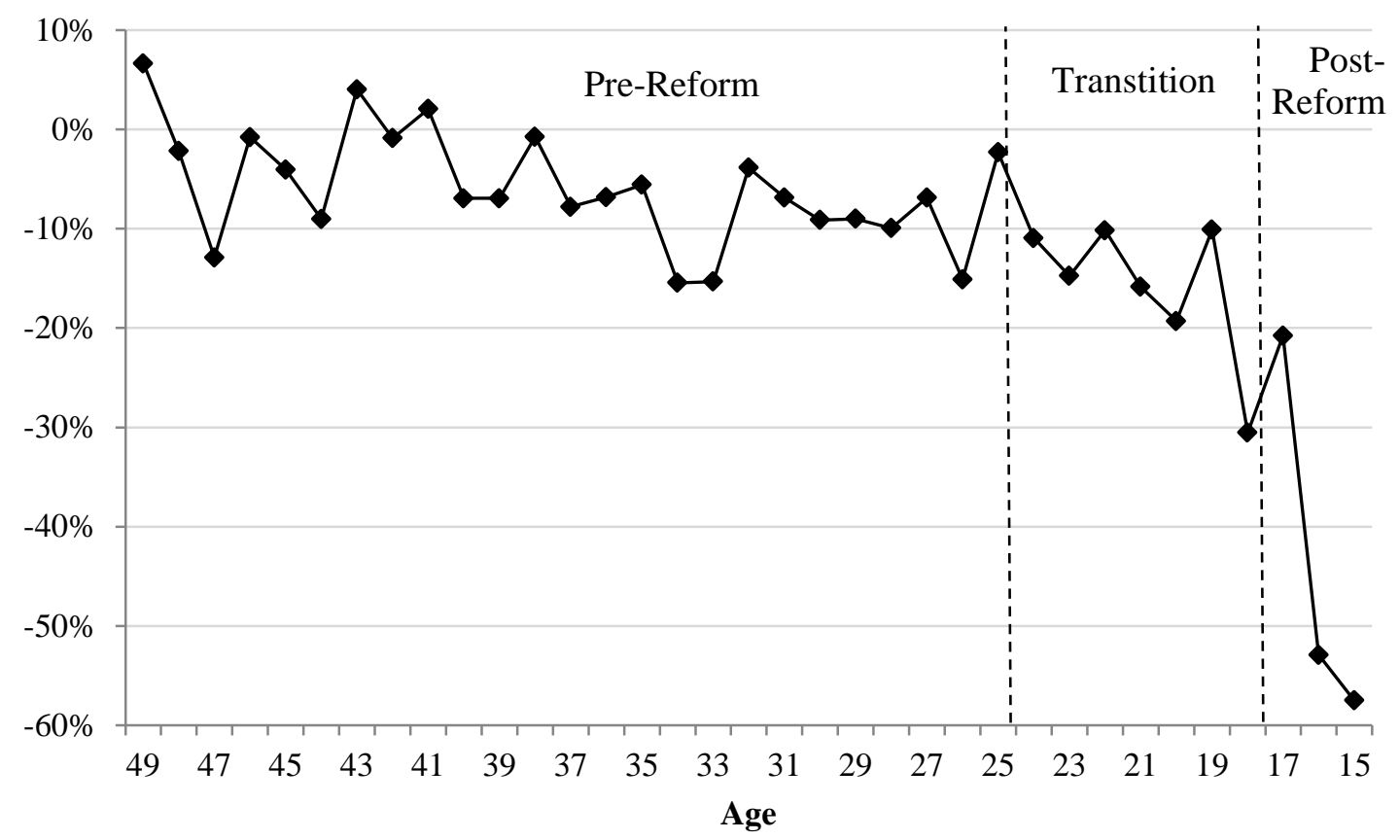


Figure 9 - 2SLS: Coefficient Estimates for the Effect of an Additional Year of Schooling

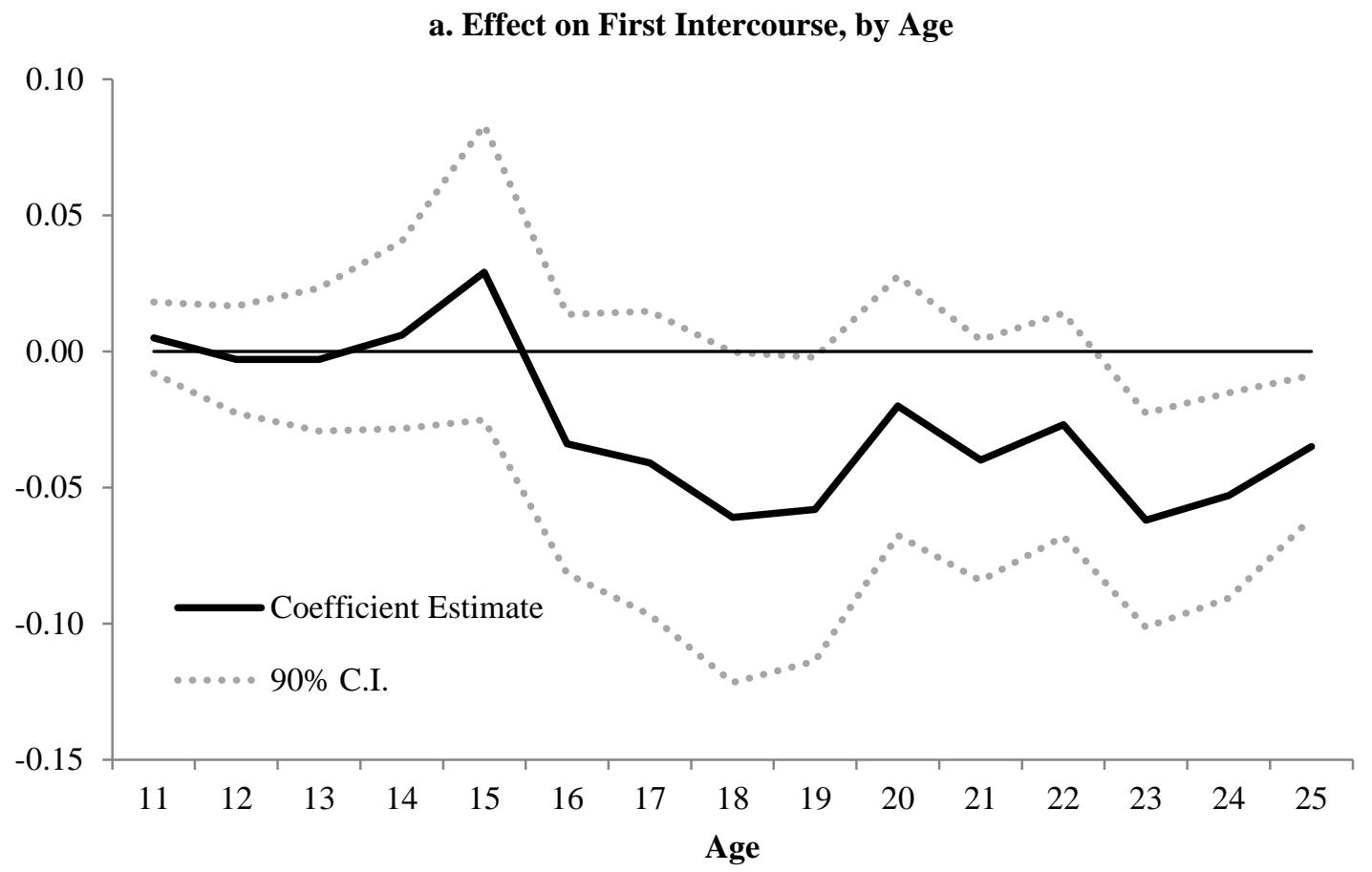

b. Effect on First Marriage, by Age

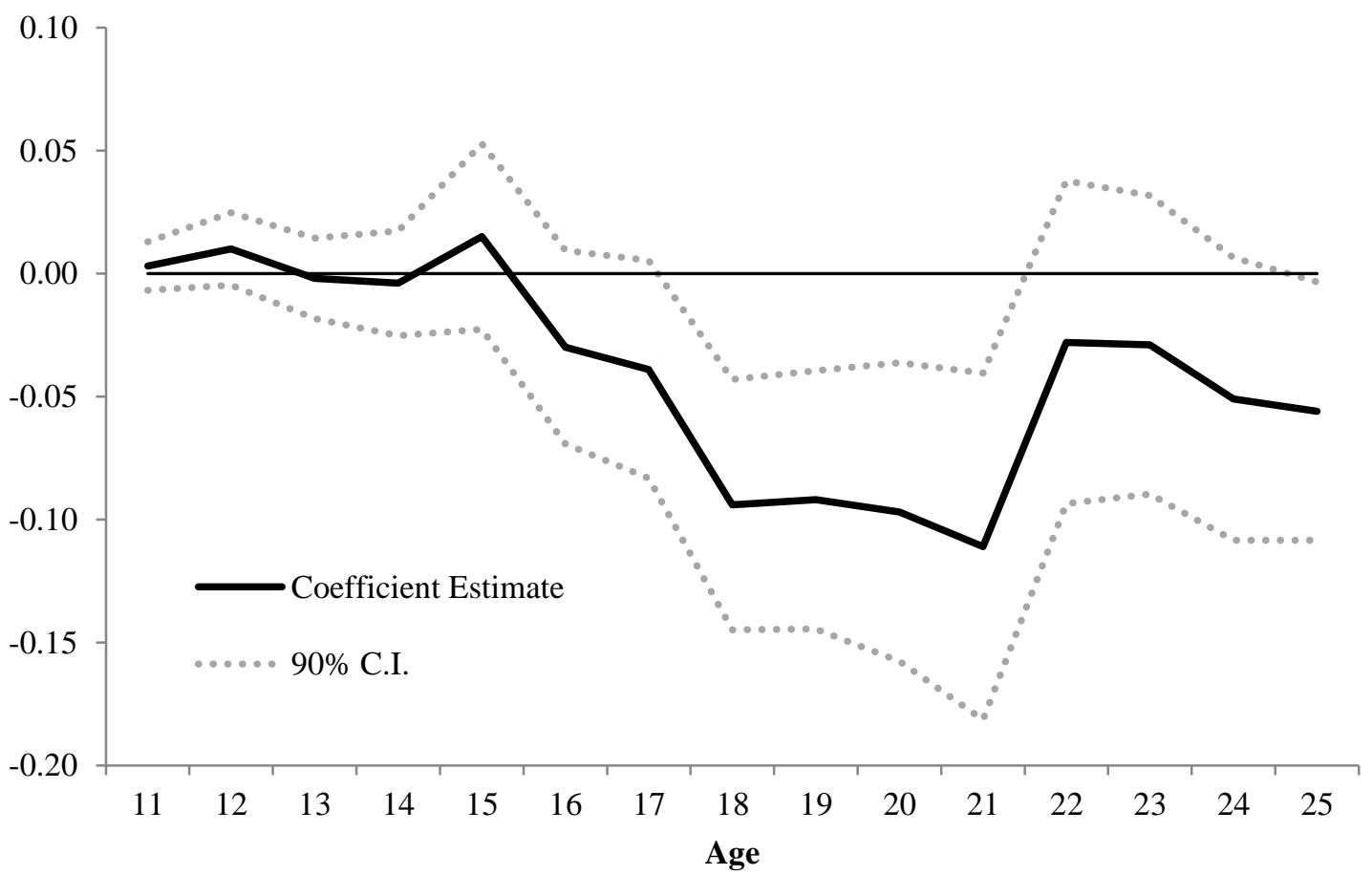




\section{c. Effect on First Birth, by Age}

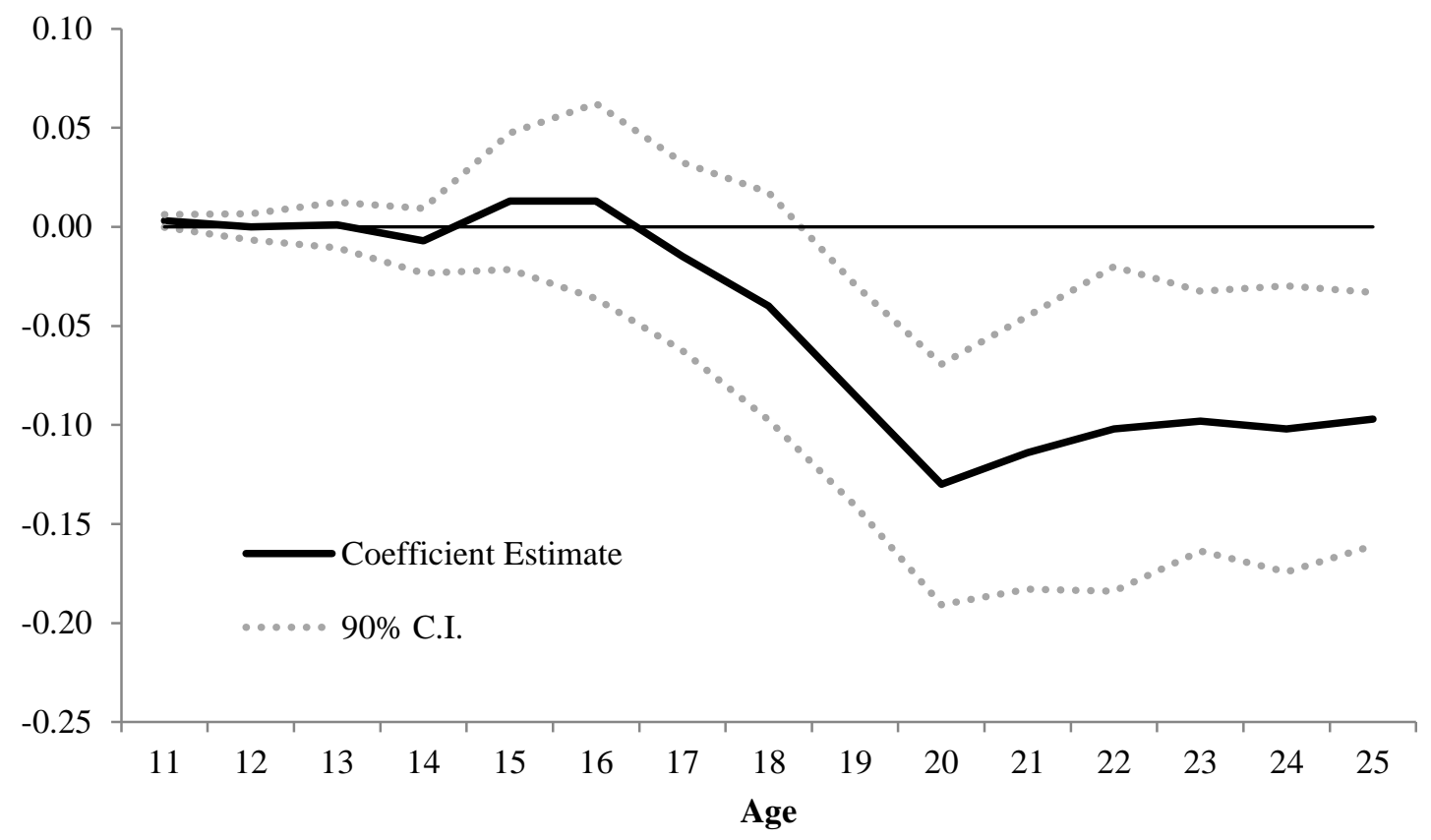

d. Effect on Total Fertility, by Age

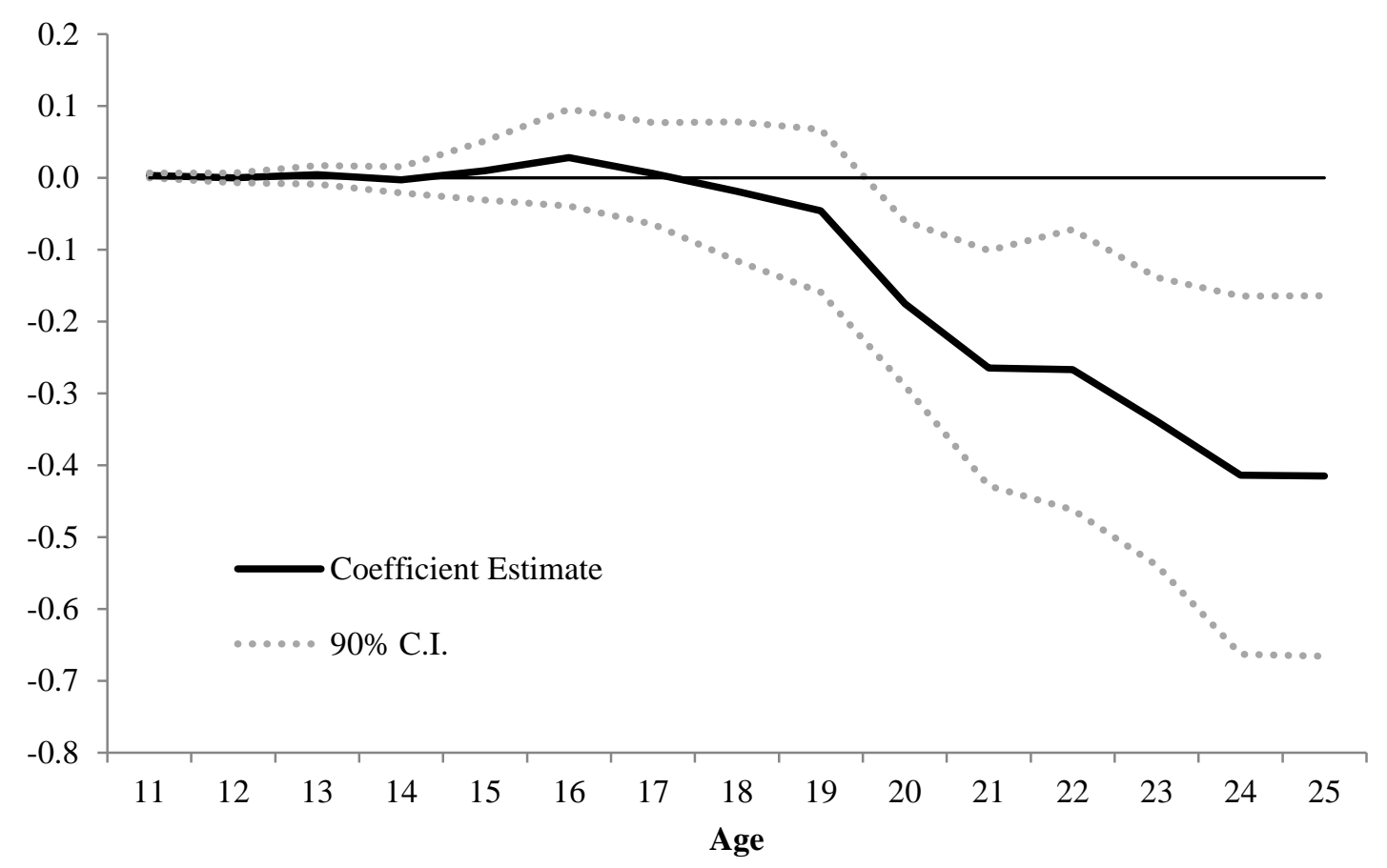


Table 1 - Summary Statistics

\begin{tabular}{|c|c|c|}
\hline & Mean & Std. Dev. \\
\hline Age & 28.07 & $(8.19)$ \\
\hline Years of School & 7.688 & $(3.599)$ \\
\hline Fraction with at Least 8 Years of School & 0.521 & \\
\hline Age at First Intercourse & 16.87 & $(3.01)$ \\
\hline Age at First Marriage & 18.91 & $(3.77)$ \\
\hline Age at First Birth & 19.10 & $(3.34)$ \\
\hline \multicolumn{3}{|l|}{ Fraction with First Intercourse by age: } \\
\hline 15 & 0.317 & \\
\hline 18 & 0.722 & \\
\hline 21 & 0.907 & \\
\hline 25 & 0.977 & \\
\hline \multicolumn{3}{|l|}{ Fraction Married by age: } \\
\hline 15 & 0.117 & \\
\hline 18 & 0.397 & \\
\hline 21 & 0.673 & \\
\hline 25 & 0.855 & \\
\hline \multicolumn{3}{|l|}{ Fraction with First Birth by age: } \\
\hline 15 & 0.078 & \\
\hline 18 & 0.392 & \\
\hline 21 & 0.713 & \\
\hline 25 & 0.894 & \\
\hline \multicolumn{3}{|l|}{ Total Fertility by age: } \\
\hline 15 & 0.092 & $(0.337)$ \\
\hline 18 & 0.544 & $(0.793)$ \\
\hline 21 & 1.363 & (1.187) \\
\hline 25 & 2.538 & $(1.579)$ \\
\hline Fraction Working & 0.508 & \\
\hline Ideal Number of Children & 3.60 & $(1.659)$ \\
\hline
\end{tabular}

Source: Demographic and Health Survey: 1989, 1993, 1998, 2003, and 2008. Sample includes women born between 1950 and 1980 . 
Table 2 - DHS Education Variables

\begin{tabular}{cc}
\hline A. Highest Education Level Attended & B. Highest Year of Education \\
\hline & 0 \\
& 1 \\
0 - No Education & 2 \\
1- Primary & 3 \\
2- Secondary & 4 \\
3- Tertiary & 5 \\
& 6 \\
& 7 \\
& 8 \\
& 9 \\
& 10 \\
\hline
\end{tabular}


Table 3 - OLS: Schooling and First Birth and Total Fertility, by Age

\begin{tabular}{|c|c|c|c|c|c|c|c|c|c|c|c|}
\hline \multicolumn{12}{|c|}{ A. First Intercourse by Age: } \\
\hline \multirow[b]{2}{*}{ Yrsschl } & 15 & 16 & 17 & 18 & 19 & 20 & 21 & 22 & 23 & 24 & 25 \\
\hline & $\begin{array}{c}-0.040 * * * \\
(0.001)\end{array}$ & $\begin{array}{c}-0.047 * * * \\
(0.001)\end{array}$ & $\begin{array}{c}-0.049 * * * \\
(0.001)\end{array}$ & $\begin{array}{c}-0.045^{* * *} \\
(0.001)\end{array}$ & $\begin{array}{c}-0.040 * * * \\
(0.001)\end{array}$ & $\begin{array}{c}-0.028 * * * \\
(0.001)\end{array}$ & $\begin{array}{c}-0.023 * * * \\
(0.001)\end{array}$ & $\begin{array}{c}-0.017 * * * \\
(0.001)\end{array}$ & $\begin{array}{c}-0.013 * * * \\
(0.001)\end{array}$ & $\begin{array}{c}-0.009 * * * \\
(0.001)\end{array}$ & $\begin{array}{c}-0.006^{* * * *} \\
(0.001)\end{array}$ \\
\hline $\mathrm{N}$ & 18,645 & 18,059 & 17,308 & 16,495 & 15,657 & 14,842 & 14,192 & 13,417 & 12,489 & 11,598 & 10,790 \\
\hline \multicolumn{12}{|c|}{ B. First Marriage by Age: } \\
\hline \multirow[b]{2}{*}{ Yrsschl } & 15 & 16 & 17 & 18 & 19 & 20 & 21 & 22 & 23 & 24 & 25 \\
\hline & $\begin{array}{c}-0.025^{* * *} \\
(0.001)\end{array}$ & $\begin{array}{c}-0.035^{* * *} \\
(0.001)\end{array}$ & $\begin{array}{c}-0.045^{* * *} \\
(0.001)\end{array}$ & $\begin{array}{c}-0.050^{* * * *} \\
(0.001)\end{array}$ & $\begin{array}{c}-0.050 * * * \\
(0.001)\end{array}$ & $\begin{array}{c}-0.045^{* * *} \\
(0.001)\end{array}$ & $\begin{array}{c}-0.040 * * * \\
(0.001)\end{array}$ & $\begin{array}{c}-0.034 * * * \\
(0.001)\end{array}$ & $\begin{array}{c}-0.029 * * * \\
(0.002)\end{array}$ & $\begin{array}{c}-0.022 * * * \\
(0.001)\end{array}$ & $\begin{array}{c}-0.017 * * * \\
(0.001)\end{array}$ \\
\hline $\mathrm{N}$ & 19,029 & 18,439 & 17,678 & 16,859 & 16,010 & 15,166 & 14,505 & 13,718 & 12,769 & 11,849 & 11,021 \\
\hline \multicolumn{12}{|c|}{ C. First Birth by Age: } \\
\hline \multirow[b]{2}{*}{ Yrsschl } & 15 & 16 & 17 & 18 & 19 & 20 & 21 & 22 & 23 & 24 & 25 \\
\hline & $\begin{array}{c}-0.016 * * * \\
(0.001)\end{array}$ & $\begin{array}{c}-0.027 * * * \\
(0.001)\end{array}$ & $\begin{array}{c}-0.038^{* * *} \\
(0.001)\end{array}$ & $\begin{array}{c}-0.046^{* * *} * \\
(0.001)\end{array}$ & $\begin{array}{c}-0.050 * * * \\
(0.001)\end{array}$ & $\begin{array}{c}-0.049 * * * \\
(0.001)\end{array}$ & $\begin{array}{c}-0.044 * * * \\
(0.002)\end{array}$ & $\begin{array}{c}-0.037 * * * \\
(0.002)\end{array}$ & $\begin{array}{c}-0.030 * * * \\
(0.002)\end{array}$ & $\begin{array}{c}-0.023 * * * \\
(0.001)\end{array}$ & $\begin{array}{c}-0.018 * * * \\
(0.001)\end{array}$ \\
\hline $\mathrm{N}$ & 19,029 & 18,439 & 17,678 & 16,859 & 16,010 & 15,166 & 14,505 & 13,718 & 12,769 & 11,849 & 11,021 \\
\hline \multicolumn{12}{|c|}{ D. Total Fertility by Age: } \\
\hline \multirow[b]{2}{*}{ Yrsschl } & 15 & 16 & 17 & 18 & 19 & 20 & 21 & 22 & 23 & 24 & 25 \\
\hline & $\begin{array}{c}-0.021 * * * \\
(0.001)\end{array}$ & $\begin{array}{c}-0.036 * * * \\
(0.002)\end{array}$ & $\begin{array}{c}-0.055^{* * *} \\
(0.002)\end{array}$ & $\begin{array}{c}-0.076 \text { *** } \\
(0.002)\end{array}$ & $\begin{array}{c}-0.096 * * * \\
(0.003)\end{array}$ & $\begin{array}{c}-0.114 * * * \\
(0.003)\end{array}$ & $\begin{array}{c}-0.127 * * * \\
(0.004)\end{array}$ & $\begin{array}{c}-0.135 * * * \\
(0.004)\end{array}$ & $\begin{array}{c}-0.143 * * * \\
(0.005)\end{array}$ & $\begin{array}{c}-0.148^{* * *} \\
(0.005)\end{array}$ & $\begin{array}{c}-0.147 * * * \\
(0.006)\end{array}$ \\
\hline $\mathrm{N}$ & 19,029 & 18,439 & 17,678 & 16,859 & 16,010 & 15,166 & 14,505 & 13,718 & 12,769 & 11,849 & 11,021 \\
\hline
\end{tabular}

$* * * \mathrm{p}<0.01, * * \mathrm{p}<0.05, * \mathrm{p}<0.1$. Each estimate is from a separate regression. In panels $\mathrm{A}, \mathrm{B}$, and $\mathrm{C}$ the dependent variable is equal to one if the event occurred by the given age, in panel $\mathrm{D}$ the dependent variable is total fertility by the given age. The sample is restricted to only include observations older than the age specified in each column. The sample includes women in birth cohorts from 1950 to 1980. All regressions include a cubic for age, a quadratic quarterly time trend, and fixed effects for quarter of birth, ethnicity, and type of childhood residence. Each regression is weighted by sampling weights from the DHS, and standard errors are clustered at the birth quarter (cohort and quarter) level. 
Table 4 - First Stage

\begin{tabular}{|c|c|c|c|}
\hline & $\begin{array}{c}\text { Years of Schooling } \\
\text { (1) }\end{array}$ & $\begin{array}{c}\text { AtLeast8 } \\
(2)\end{array}$ & $\begin{array}{c}\text { Education } 8 \\
(3)\end{array}$ \\
\hline Inst $_{\mathrm{c}}$ & $\begin{array}{c}0.740 * * * \\
(0.153)\end{array}$ & $\begin{array}{c}0.233 * * * \\
(0.023)\end{array}$ & $\begin{array}{c}0.274 * * * \\
(0.016)\end{array}$ \\
\hline F-Statistic & 23.47 & 101.68 & 281.90 \\
\hline $\mathrm{N}$ & 19,631 & 19,631 & 19,631 \\
\hline
\end{tabular}

$* * * \mathrm{p}<0.01, * * \mathrm{p}<0.05, * \mathrm{p}<0.1$. Each estimate is from a separate regression. The dependent variable is a measure of education. The years of schooling variable is taken from the DHS, atleast 8 and education 8 are calculated as explained in the text. Inst $t_{\mathrm{c}}$ is the probability of being treated by the 1985 reform, the variable ranges from 0 to 1 . Sample includes women in birth cohorts from 1950 to 1980 . All regressions include a cubic for age, a quadratic quarterly time trend, and fixed effects for quarter of birth, ethnicity, and type of childhood residence. Each regression is weighted by sampling weights from the DHS, and standard errors are clustered at the birth quarter (cohort and quarter) level. 
Table 5 - Reduced From: Age at First Intercourse/Marriage/Birth and Total Fertility, by Age

\begin{tabular}{|c|c|c|c|c|c|c|c|c|c|c|c|}
\hline \multicolumn{12}{|c|}{ A. First Intercourse by Age: } \\
\hline & 15 & 16 & 17 & 18 & 19 & 20 & 21 & 22 & 23 & 24 & 25 \\
\hline Inst $_{c}$ & $\begin{array}{c}0.020 \\
(0.020)\end{array}$ & $\begin{array}{l}-0.023 \\
(0.022)\end{array}$ & $\begin{array}{c}-0.028 \\
(0.025)\end{array}$ & $\begin{array}{c}-0.040 \\
(0.028)\end{array}$ & $\begin{array}{c}-0.038 \\
(0.024)\end{array}$ & $\begin{array}{c}-0.015 \\
(0.020)\end{array}$ & $\begin{array}{c}-0.025 \\
(0.016)\end{array}$ & $\begin{array}{c}-0.016 \\
(0.015)\end{array}$ & $\begin{array}{c}-0.043 * * * \\
(0.012)\end{array}$ & $\begin{array}{c}-0.038 * * * \\
(0.011)\end{array}$ & $\begin{array}{c}-0.028 * * * \\
(0.010)\end{array}$ \\
\hline $\mathrm{N}$ & 18,645 & 18,059 & 17,308 & 16,495 & 15,657 & 14,842 & 14,192 & 13,417 & 12,489 & 11,598 & 10,790 \\
\hline
\end{tabular}

\begin{tabular}{|c|c|c|c|c|c|c|c|c|c|c|c|}
\hline \multicolumn{12}{|c|}{ B. First Marriage by Age: } \\
\hline & 15 & 16 & 17 & 18 & 19 & 20 & 21 & 22 & 23 & 24 & 25 \\
\hline Inst $_{\mathrm{c}}$ & $\begin{array}{c}0.010 \\
(0.015)\end{array}$ & $\begin{array}{l}-0.020 \\
(0.017)\end{array}$ & $\begin{array}{l}-0.026 \\
(0.019)\end{array}$ & $\begin{array}{c}-0.062 * * * \\
(0.022)\end{array}$ & $\begin{array}{c}-0.059 * * \\
(0.023)\end{array}$ & $\begin{array}{c}-0.063 * * * \\
(0.024)\end{array}$ & $\begin{array}{c}-0.068 * * * \\
(0.023)\end{array}$ & $\begin{array}{c}-0.017 \\
(0.024)\end{array}$ & $\begin{array}{l}-0.020 \\
(0.026)\end{array}$ & $\begin{array}{l}-0.036 \\
(0.023)\end{array}$ & $\begin{array}{c}-0.044 * * \\
(0.021)\end{array}$ \\
\hline $\mathrm{N}$ & 19,029 & 18,439 & 17,678 & 16,859 & 16,010 & 15,166 & 14,505 & 13,718 & 12,769 & 11,849 & 11,021 \\
\hline
\end{tabular}

\begin{tabular}{|c|c|c|c|c|c|c|c|c|c|c|c|}
\hline \multicolumn{12}{|c|}{ C. First Birth by Age: } \\
\hline & 15 & 16 & 17 & 18 & 19 & 20 & 21 & 22 & 23 & 24 & 25 \\
\hline Inst $_{\mathrm{c}}$ & $\begin{array}{c}0.009 \\
(0.013)\end{array}$ & $\begin{array}{c}0.008 \\
(0.019)\end{array}$ & $\begin{array}{l}-0.010 \\
(0.020)\end{array}$ & $\begin{array}{c}-0.026 \\
(0.025)\end{array}$ & $\begin{array}{c}-0.055^{* *} \\
(0.026)\end{array}$ & $\begin{array}{c}-0.084 * * * \\
(0.024)\end{array}$ & $\begin{array}{c}-0.070 * * \\
(0.029)\end{array}$ & $\begin{array}{c}-0.060 * * \\
(0.029)\end{array}$ & $\begin{array}{c}-0.068 * * \\
(0.027)\end{array}$ & $\begin{array}{c}-0.072 * * \\
(0.029)\end{array}$ & $\begin{array}{c}-0.076^{* * * *} \\
(0.023)\end{array}$ \\
\hline $\mathrm{N}$ & 19,029 & 18,439 & 17,678 & 16,859 & 16,010 & 15,166 & 14,505 & 13,718 & 12,769 & 11,849 & 11,021 \\
\hline
\end{tabular}

\begin{tabular}{|c|c|c|c|c|c|c|c|c|c|c|c|}
\hline \multicolumn{12}{|c|}{ D. Total Fertility by Age: } \\
\hline & 15 & 16 & 17 & 18 & 19 & 20 & 21 & 22 & 23 & 24 & 25 \\
\hline Inst $_{\mathrm{c}}$ & $\begin{array}{c}0.007 \\
(0.016)\end{array}$ & $\begin{array}{c}0.018 \\
(0.025)\end{array}$ & $\begin{array}{c}0.004 \\
(0.028)\end{array}$ & $\begin{array}{l}-0.013 \\
(0.040)\end{array}$ & $\begin{array}{l}-0.030 \\
(0.047)\end{array}$ & $\begin{array}{c}-0.113 * * \\
(0.050)\end{array}$ & $\begin{array}{c}-0.162 * * \\
(0.066)\end{array}$ & $\begin{array}{c}-0.157 * * \\
(0.073)\end{array}$ & $\begin{array}{c}-0.235 * * * \\
(0.087)\end{array}$ & $\begin{array}{c}-0.292 * * * \\
(0.100)\end{array}$ & $\begin{array}{c}-0.324 * * * \\
(0.108)\end{array}$ \\
\hline $\mathrm{N}$ & 19,029 & 18,439 & 17,678 & 16,859 & 16,010 & 15,166 & 14,505 & 13,718 & 12,769 & 11,849 & 11,021 \\
\hline
\end{tabular}

$* * * \mathrm{p}<0.01, * * \mathrm{p}<0.05, * \mathrm{p}<0.1$. Each estimate is from a separate regression. In panels $\mathrm{A}, \mathrm{B}$, and $\mathrm{C}$ the dependent variable is equal to one if the event occurred by the given age, in panel $\mathrm{D}$ the dependent variable is total fertility by the given age. The sample is restricted to only include observations older than the age specified in each column. Inst $\mathrm{c}_{\mathrm{c}}$ is the probability of being treated by the 1985 reform, the variable ranges from 0 to 1 . Sample includes women in birth cohorts from 1950 to 1980 . All regressions include a cubic for age, a quadratic quarterly time trend, and fixed effects for quarter of birth, ethnicity, and type of childhood residence. Each regression is weighted by sampling weights from the DHS, and standard errors are clustered at the birth cohort (year and quarter) level. 
Table 6 - Reduced From with Control for Grade One Enrollment: Age at First Intercourse/Marriage/Birth and Total Fertility, by Age

\begin{tabular}{|c|c|c|c|c|c|c|c|c|c|c|c|}
\hline \multicolumn{12}{|c|}{ A. First Intercourse by Age: } \\
\hline \multirow{3}{*}{ Inst $_{c}$} & 15 & 16 & 17 & 18 & 19 & 20 & 21 & 22 & 23 & 24 & 25 \\
\hline & 0.009 & -0.034 & -0.032 & -0.041 & -0.040 & -0.022 & -0.027 & -0.025 & $-0.044 * * *$ & $-0.038 * * *$ & $-0.031 * * *$ \\
\hline & $(0.020)$ & $(0.025)$ & $(0.028)$ & $(0.031)$ & $(0.027)$ & $(0.022)$ & $(0.019)$ & $(0.017)$ & $(0.013)$ & $(0.012)$ & $(0.010)$ \\
\hline $\mathrm{N}$ & 18,645 & 18,059 & 17,308 & 16,495 & 15,657 & 14,842 & 14,192 & 13,417 & 12,489 & 11,598 & 10,790 \\
\hline
\end{tabular}

\begin{tabular}{|c|c|c|c|c|c|c|c|c|c|c|c|}
\hline \multicolumn{12}{|c|}{ B. First Marriage by Age: } \\
\hline \multirow{3}{*}{ Inst $_{c}$} & 15 & 16 & 17 & 18 & 19 & 20 & 21 & 22 & 23 & 24 & 25 \\
\hline & 0.008 & -0.027 & -0.031 & $-0.072 * * *$ & $-0.064 * * *$ & $-0.063 * *$ & $-0.068 * * *$ & 0.002 & -0.015 & -0.029 & -0.040 \\
\hline & $(0.015)$ & $(0.018)$ & $(0.020)$ & $(0.024)$ & $(0.024)$ & $(0.025)$ & $(0.025)$ & $(0.027)$ & $(0.028)$ & $(0.026)$ & $(0.027)$ \\
\hline $\mathrm{N}$ & 19,029 & 18,439 & 17,678 & 16,859 & 16,010 & 15,166 & 14,505 & 13,718 & 12,769 & 11,849 & 11,021 \\
\hline
\end{tabular}

\begin{tabular}{|c|c|c|c|c|c|c|c|c|c|c|c|}
\hline \multicolumn{12}{|c|}{ C. First Birth by Age: } \\
\hline & 15 & 16 & 17 & 18 & 19 & 20 & 21 & 22 & 23 & 24 & 25 \\
\hline Inst $_{\mathrm{c}}$ & $\begin{array}{c}0.001 \\
(0.013)\end{array}$ & $\begin{array}{c}0.006 \\
(0.018)\end{array}$ & $\begin{array}{c}-0.017 \\
(0.021)\end{array}$ & $\begin{array}{l}-0.045 \\
(0.029)\end{array}$ & $\begin{array}{c}-0.062 * * \\
(0.030)\end{array}$ & $\begin{array}{c}-0.080 * * * \\
(0.027)\end{array}$ & $\begin{array}{c}-0.072 * * \\
(0.034)\end{array}$ & $\begin{array}{c}-0.058 \\
(0.037)\end{array}$ & $\begin{array}{c}-0.063 * \\
(0.033)\end{array}$ & $\begin{array}{c}-0.070 * * \\
(0.035)\end{array}$ & $\begin{array}{c}-0.070 * * \\
(0.027)\end{array}$ \\
\hline $\mathrm{N}$ & 19,029 & 18,439 & 17,678 & 16,859 & 16,010 & 15,166 & 14,505 & 13,718 & 12,769 & 11,849 & 11,021 \\
\hline
\end{tabular}

\begin{tabular}{|c|c|c|c|c|c|c|c|c|c|c|c|}
\hline \multicolumn{12}{|c|}{ D. Total Fertility by Age: } \\
\hline & 15 & 16 & 17 & 18 & 19 & 20 & 21 & 22 & 23 & 24 & 25 \\
\hline Inst $_{c}$ & $\begin{array}{c}0.001 \\
(0.015)\end{array}$ & $\begin{array}{c}0.017 \\
(0.023)\end{array}$ & $\begin{array}{l}-0.004 \\
(0.026)\end{array}$ & $\begin{array}{l}-0.042 \\
(0.042)\end{array}$ & $\begin{array}{l}-0.051 \\
(0.054)\end{array}$ & $\begin{array}{c}-0.130 * * \\
(0.056)\end{array}$ & $\begin{array}{c}-0.196 * * \\
(0.077)\end{array}$ & $\begin{array}{c}-0.182 * * \\
(0.085)\end{array}$ & $\begin{array}{c}-0.257 * * \\
(0.099)\end{array}$ & $\begin{array}{c}-0.316 * * * \\
(0.110)\end{array}$ & $\begin{array}{c}-0.331 * * * \\
(0.119)\end{array}$ \\
\hline $\mathrm{N}$ & 19,029 & 18,707 & 18,011 & 17,110 & 16,248 & 15,337 & 14,665 & 13,856 & 12,889 & 11,954 & 11,105 \\
\hline
\end{tabular}

$* * * \mathrm{p}<0.01, * * \mathrm{p}<0.05, * \mathrm{p}<0.1$. Each estimate is from a separate regression. In panels $\mathrm{A}, \mathrm{B}$, and $\mathrm{C}$ the dependent variable is equal to one if the event occurred by the given age, in panel

$\mathrm{D}$ the dependent variable is total fertility by the given age. The sample is restricted to only include observations older than the age specified in each column. Inst $\mathrm{c}_{\mathrm{c}}$ is the probability of being treated by the 1985 reform, the variable ranges from 0 to 1 . Sample includes women in birth cohorts from 1950 to 1980 . All regressions include a cubic for age, a quadratic

quarterly time trend, the number of students enrolled in grade one during the respondent's age 6 year, and fixed effects for quarter of birth, ethnicity, and type of childhood residence.

Each regression is weighted by sampling weights from the DHS, and standard errors are clustered at the birth cohort (year and quarter) level. 
Table 7 - Reduced From using an Alternative Instrument: Age at First Intercourse/Marriage/Birth and Total Fertility, by Age

\begin{tabular}{lccccccccccc}
\hline \multicolumn{2}{l}{ A. First Intercourse by Age: } & 15 & 16 & 17 & 18 & 19 & 20 & 21 & 22 & 23 & 24 \\
Alternative & 0.007 & -0.034 & -0.042 & $-0.056^{* *}$ & $-0.052^{* *}$ & -0.022 & $-0.032^{*}$ & -0.021 & $-0.050^{* * *}$ & $-0.043^{* * *}$ & $-0.033^{* * *}$ \\
Instrument $_{\mathrm{c}}$ & $(0.021)$ & $(0.023)$ & $(0.027)$ & $(0.027)$ & $(0.025)$ & $(0.021)$ & $(0.018)$ & $(0.017)$ & $(0.013)$ & $(0.012)$ & $(0.012)$ \\
& & & & & & & & & & & \\
$\mathrm{N}$ & 18,645 & 18,059 & 17,308 & 16,495 & 15,657 & 14,842 & 14,192 & 13,417 & 12,489 & 11,598 & 10,790
\end{tabular}

\begin{tabular}{|c|c|c|c|c|c|c|c|c|c|c|c|}
\hline \multicolumn{12}{|c|}{ B. First Marriage by Age: } \\
\hline & 15 & 16 & 17 & 18 & 19 & 20 & 21 & 22 & 23 & 24 & 25 \\
\hline $\begin{array}{l}\text { Alternative } \\
\text { Instrument }_{c}\end{array}$ & $\begin{array}{c}0.008 \\
(0.016)\end{array}$ & $\begin{array}{c}-0.022 \\
(0.019)\end{array}$ & $\begin{array}{l}-0.027 \\
(0.022)\end{array}$ & $\begin{array}{c}-0.067 * * * \\
(0.023)\end{array}$ & $\begin{array}{c}-0.060 * * \\
(0.024)\end{array}$ & $\begin{array}{c}-0.073 * * * \\
(0.025)\end{array}$ & $\begin{array}{c}-0.076^{* * * *} \\
(0.025)\end{array}$ & $\begin{array}{l}-0.019 \\
(0.025)\end{array}$ & $\begin{array}{l}-0.017 \\
(0.029)\end{array}$ & $\begin{array}{l}-0.038 \\
(0.027)\end{array}$ & $\begin{array}{c}-0.051 * * \\
(0.025)\end{array}$ \\
\hline $\mathrm{N}$ & 19,029 & 18,439 & 17,678 & 16,859 & 16,010 & 15,166 & 14,505 & 13,718 & 12,769 & 11,849 & 11,021 \\
\hline
\end{tabular}

\begin{tabular}{|c|c|c|c|c|c|c|c|c|c|c|c|}
\hline \multicolumn{12}{|c|}{ C. First Birth by Age: } \\
\hline & 15 & 16 & 17 & 18 & 19 & 20 & 21 & 22 & 23 & 24 & 25 \\
\hline Alternative & 0.008 & -0.004 & -0.019 & -0.036 & $-0.069 * *$ & $-0.095 * * *$ & $-0.074 * *$ & $-0.065^{* *}$ & $-0.064 * *$ & $-0.072 * * *$ & $-0.083 * * *$ \\
\hline Instrument $_{\mathrm{c}}$ & $(0.013)$ & $(0.019)$ & $(0.022)$ & $(0.027)$ & $(0.029)$ & $(0.026)$ & $(0.031)$ & $(0.028)$ & $(0.025)$ & $(0.026)$ & $(0.026)$ \\
\hline $\mathrm{N}$ & 19,029 & 18,439 & 17,678 & 16,859 & 16,010 & 15,166 & 14,505 & 13,718 & 12,769 & 11,849 & 11,021 \\
\hline
\end{tabular}

\begin{tabular}{|c|c|c|c|c|c|c|c|c|c|c|c|}
\hline \multicolumn{12}{|c|}{ D. Total Fertility by Age: } \\
\hline & 15 & 16 & 17 & 18 & 19 & 20 & 21 & 22 & 23 & 24 & 25 \\
\hline $\begin{array}{l}\text { Alternative } \\
\text { Instrument }_{c}\end{array}$ & $\begin{array}{c}0.005 \\
(0.016)\end{array}$ & $\begin{array}{c}0.006 \\
(0.025)\end{array}$ & $\begin{array}{c}-0.009 \\
(0.029)\end{array}$ & $\begin{array}{l}-0.025 \\
(0.040)\end{array}$ & $\begin{array}{l}-0.039 \\
(0.051)\end{array}$ & $\begin{array}{c}-0.132 * * * \\
(0.049)\end{array}$ & $\begin{array}{c}-0.182 * * * \\
(0.065)\end{array}$ & $\begin{array}{c}-0.173^{* *} * \\
(0.074)\end{array}$ & $\begin{array}{c}-0.235 * * * \\
(0.087)\end{array}$ & $\begin{array}{c}-0.284 * * * \\
(0.095)\end{array}$ & $\begin{array}{c}-0.302 * * * \\
(0.107)\end{array}$ \\
\hline $\mathrm{N}$ & 19,029 & 18,439 & 17,678 & 16,859 & 16,010 & 15,166 & 14,505 & 13,718 & 12,769 & 11,849 & 11,021 \\
\hline
\end{tabular}

$* * * \mathrm{p}<0.01, * * \mathrm{p}<0.05, * \mathrm{p}<0.1$. Each estimate is from a separate regression. In panels $\mathrm{A}, \mathrm{B}$, and $\mathrm{C}$ the dependent variable is equal to one if the event occurred by the given age, in panel $\mathrm{D}$ the dependent variable is total fertility by the given age. The sample is restricted to only include observations older than the age specified in each column. Alternative Instrument $\mathrm{c}_{\mathrm{c}}$ is calculated without using enrollment data, as outlined in the text. It is the estimated probability of being treated by the 1985 reform, the variable ranges from 0 to 1 . Sample includes women in birth cohorts from 1950 to 1980. All regressions include a cubic for age, a quadratic quarterly time trend, and fixed effects for quarter of birth, ethnicity, and type of childhood residence. Each regression is weighted by sampling weights from the DHS, and standard errors are clustered at the birth cohort (year and quarter) level. 
Table 8 - Reduced-form, Only Women with Less Than Five Years of School: Age at First Intercourse/Marriage/Birth and Total Fertility, by Age

\begin{tabular}{|c|c|c|c|c|c|c|c|c|c|c|c|}
\hline \multicolumn{12}{|c|}{ A. First Intercourse by Age: } \\
\hline & 15 & 16 & 17 & 18 & 19 & 20 & 21 & 22 & 23 & 24 & 25 \\
\hline Inst $_{c}$ & $\begin{array}{c}-0.037 \\
(0.060)\end{array}$ & $\begin{array}{c}-0.014 \\
(0.064)\end{array}$ & $\begin{array}{c}0.027 \\
(0.056)\end{array}$ & $\begin{array}{c}0.036 \\
(0.042)\end{array}$ & $\begin{array}{c}0.035 \\
(0.040)\end{array}$ & $\begin{array}{c}0.037 \\
(0.037)\end{array}$ & $\begin{array}{c}0.037 \\
(0.036)\end{array}$ & $\begin{array}{c}0.035 \\
(0.040)\end{array}$ & $\begin{array}{c}0.030 \\
(0.044)\end{array}$ & $\begin{array}{c}0.038 \\
(0.051)\end{array}$ & $\begin{array}{c}0.026 \\
(0.053)\end{array}$ \\
\hline $\mathrm{N}$ & 2,793 & 2,759 & 2,705 & 2,649 & 2,596 & 2,516 & 2,458 & 2,391 & 2,313 & 2,219 & 2,134 \\
\hline
\end{tabular}

\begin{tabular}{|c|c|c|c|c|c|c|c|c|c|c|c|}
\hline \multicolumn{12}{|c|}{ B. First Marriage by Age: } \\
\hline & 15 & 16 & 17 & 18 & 19 & 20 & 21 & 22 & 23 & 24 & 25 \\
\hline Inst $_{c}$ & $\begin{array}{c}-0.043 \\
(0.065)\end{array}$ & $\begin{array}{l}-0.016 \\
(0.077)\end{array}$ & $\begin{array}{c}0.006 \\
(0.069)\end{array}$ & $\begin{array}{c}0.007 \\
(0.063)\end{array}$ & $\begin{array}{c}0.071 \\
(0.066)\end{array}$ & $\begin{array}{c}0.096 \\
(0.065)\end{array}$ & $\begin{array}{c}0.073 \\
(0.061)\end{array}$ & $\begin{array}{c}0.069 \\
(0.058)\end{array}$ & $\begin{array}{c}0.077 \\
(0.063)\end{array}$ & $\begin{array}{c}0.073 \\
(0.066)\end{array}$ & $\begin{array}{c}0.033 \\
(0.067)\end{array}$ \\
\hline $\mathrm{N}$ & 2,886 & 2,852 & 2,797 & 2,740 & 2,686 & 2,602 & 2,542 & 2,473 & 2,394 & 2,297 & 2,209 \\
\hline
\end{tabular}

\begin{tabular}{|c|c|c|c|c|c|c|c|c|c|c|c|}
\hline \multicolumn{12}{|c|}{ C. First Birth by Age: } \\
\hline & 15 & 16 & 17 & 18 & 19 & 20 & 21 & 22 & 23 & 24 & 25 \\
\hline Inst $_{c}$ & $\begin{array}{c}0.056 \\
(0.059)\end{array}$ & $\begin{array}{c}0.022 \\
(0.066)\end{array}$ & $\begin{array}{l}-0.061 \\
(0.064)\end{array}$ & $\begin{array}{c}0.031 \\
(0.076)\end{array}$ & $\begin{array}{c}0.009 \\
(0.056)\end{array}$ & $\begin{array}{l}-0.012 \\
(0.061)\end{array}$ & $\begin{array}{l}-0.006 \\
(0.057)\end{array}$ & $\begin{array}{c}0.005 \\
(0.067)\end{array}$ & $\begin{array}{c}0.027 \\
(0.063)\end{array}$ & $\begin{array}{c}0.021 \\
(0.068)\end{array}$ & $\begin{array}{l}-0.026 \\
(0.072)\end{array}$ \\
\hline $\mathrm{N}$ & 2,886 & 2,852 & 2,797 & 2,740 & 2,686 & 2,602 & 2,542 & 2,473 & 2,394 & 2,297 & 2,209 \\
\hline
\end{tabular}

\begin{tabular}{|c|c|c|c|c|c|c|c|c|c|c|c|}
\hline \multicolumn{12}{|c|}{ D. Total Fertility by Age: } \\
\hline & 15 & 16 & 17 & 18 & 19 & 20 & 21 & 22 & 23 & 24 & 25 \\
\hline Inst $_{\mathrm{c}}$ & $\begin{array}{c}0.038 \\
(0.089)\end{array}$ & $\begin{array}{c}0.055 \\
(0.106)\end{array}$ & $\begin{array}{c}-0.063 \\
(0.116)\end{array}$ & $\begin{array}{c}0.050 \\
(0.156)\end{array}$ & $\begin{array}{c}0.011 \\
(0.177)\end{array}$ & $\begin{array}{c}-0.038 \\
(0.213)\end{array}$ & $\begin{array}{l}-0.016 \\
(0.232)\end{array}$ & $\begin{array}{c}0.052 \\
(0.258)\end{array}$ & $\begin{array}{c}-0.010 \\
(0.292)\end{array}$ & $\begin{array}{c}0.067 \\
(0.356)\end{array}$ & $\begin{array}{c}-0.066 \\
(0.379)\end{array}$ \\
\hline $\mathrm{N}$ & 2,886 & 2,852 & 2,797 & 2,740 & 2,686 & 2,602 & 2,542 & 2,473 & 2,394 & 2,297 & 2,209 \\
\hline
\end{tabular}

$* * * \mathrm{p}<0.01, * * \mathrm{p}<0.05, * \mathrm{p}<0.1$. Each estimate is from a separate regression. In panels $\mathrm{A}, \mathrm{B}$, and $\mathrm{C}$ the dependent variable is equal to one if the event occurred by the given age, in panel

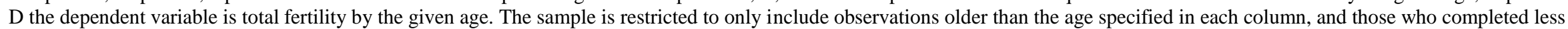
than five years of education. Inst $t_{c}$ is the probability of being treated by the 1985 reform, the variable ranges from 0 to 1 . Sample includes women in birth cohorts from 1950 to 1980 . All regressions include a cubic for age, a quadratic quarterly time trend, and fixed effects for quarter of birth, ethnicity, and type of childhood residence. Each regression is weighted by sampling weights from the DHS, and standard errors are clustered at the birth cohort (year and quarter) level. 
Table 9 - Reduced-form, Only Women who Attended College: Age at First Intercourse/Marriage/Birth and Total Fertility, by Age

\begin{tabular}{|c|c|c|c|c|c|c|c|c|c|c|c|}
\hline \multicolumn{12}{|c|}{ A. First Intercourse by Age: } \\
\hline \multirow{3}{*}{ Inst $_{\mathrm{c}}$} & 15 & 16 & 17 & 18 & 19 & 20 & 21 & 22 & 23 & 24 & 25 \\
\hline & 0.058 & 0.041 & 0.034 & -0.036 & 0.067 & 0.159 & -0.008 & -0.017 & -0.093 & -0.027 & 0.027 \\
\hline & $(0.047)$ & $(0.055)$ & $(0.074)$ & $(0.091)$ & $(0.097)$ & $(0.113)$ & $(0.111)$ & $(0.109)$ & $(0.097)$ & $(0.071)$ & $(0.063)$ \\
\hline $\mathrm{N}$ & 976 & 976 & 974 & 966 & 960 & 968 & 958 & 931 & 887 & 852 & 814 \\
\hline \multicolumn{12}{|c|}{ B. First Marriage by Age: } \\
\hline \multirow{3}{*}{ Inst $_{\mathrm{c}}$} & 15 & 16 & 17 & 18 & 19 & 20 & 21 & 22 & 23 & 24 & 25 \\
\hline & $-0.037 *$ & -0.021 & -0.035 & $-0.068^{*}$ & 0.008 & 0.065 & 0.019 & 0.030 & 0.141 & 0.135 & 0.128 \\
\hline & $(0.021)$ & $(0.026)$ & $(0.033)$ & $(0.037)$ & $(0.058)$ & $(0.062)$ & $(0.078)$ & $(0.085)$ & $(0.095)$ & $(0.106)$ & $(0.100)$ \\
\hline $\mathrm{N}$ & 981 & 981 & 979 & 971 & 965 & 973 & 963 & 936 & 892 & 857 & 819 \\
\hline \multicolumn{12}{|c|}{ C. First Birth by Age: } \\
\hline \multirow{3}{*}{ Inst $_{\mathrm{c}}$} & 15 & 16 & 17 & 18 & 19 & 20 & 21 & 22 & 23 & 24 & 25 \\
\hline & -0.026 & -0.013 & -0.007 & -0.058 & -0.035 & 0.053 & 0.099 & 0.168 & 0.045 & 0.083 & 0.073 \\
\hline & $(0.020)$ & $(0.023)$ & $(0.026)$ & $(0.036)$ & $(0.049)$ & $(0.072)$ & $(0.084)$ & $(0.103)$ & $(0.100)$ & $(0.102)$ & (0.097) \\
\hline $\mathrm{N}$ & 981 & 981 & 979 & 971 & 965 & 973 & 963 & 936 & 892 & 857 & 819 \\
\hline \multicolumn{12}{|c|}{ D. Total Fertility by Age: } \\
\hline \multirow{3}{*}{ Inst $_{c}$} & 15 & 16 & 17 & 18 & 19 & 20 & 21 & 22 & 23 & 24 & 25 \\
\hline & -0.026 & -0.013 & -0.031 & $-0.091 *$ & -0.084 & -0.010 & 0.053 & 0.110 & -0.046 & -0.031 & 0.051 \\
\hline & $(0.020)$ & $(0.023)$ & $(0.041)$ & $(0.050)$ & $(0.073)$ & $(0.107)$ & $(0.131)$ & $(0.156)$ & $(0.179)$ & $(0.213)$ & $(0.227)$ \\
\hline $\mathrm{N}$ & 981 & 981 & 979 & 971 & 965 & 973 & 963 & 936 & 892 & 857 & 819 \\
\hline
\end{tabular}

$* * * \mathrm{p}<0.01, * * \mathrm{p}<0.05, * \mathrm{p}<0.1$. Each estimate is from a separate regression. In panels $\mathrm{A}, \mathrm{B}$, and $\mathrm{C}$ the dependent variable is equal to one if the event occurred by the given age, in panel

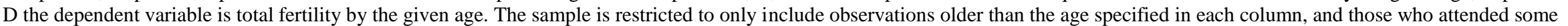
level of tertiary education. Inst ${ }_{c}$ is the probability of being treated by the 1985 reform, the variable ranges from 0 to 1 . Sample includes women in birth cohorts from 1950 to 1980 . All regressions include a cubic for age, a quadratic quarterly time trend, and fixed effects for quarter of birth, ethnicity, and type of childhood residence. Each regression is weighted by sampling weights from the DHS, and standard errors are clustered at the birth cohort (year and quarter) level. 
Table 10 - Reduced-form: Termination of Pregnancy and Marriage Characteristics

\begin{tabular}{|c|c|c|c|c|}
\hline & $\begin{array}{c}\text { Ever Had a Pregnancy } \\
\text { Terminated } \\
(1)\end{array}$ & $\begin{array}{c}\text { Husband's } \\
\text { Years of Schooling } \\
\text { (2) }\end{array}$ & $\begin{array}{c}\text { Age Difference } \\
\text { (3) }\end{array}$ & $\begin{array}{c}\text { Education } \\
\text { Difference } \\
(4) \\
\end{array}$ \\
\hline Inst $_{c}$ & $\begin{array}{l}-0.003 \\
(0.025)\end{array}$ & $\begin{array}{c}0.121 \\
(0.185)\end{array}$ & $\begin{array}{c}0.359 \\
(0.481)\end{array}$ & $\begin{array}{c}-0.441 * * \\
(0.171)\end{array}$ \\
\hline $\mathrm{N}$ & 10,827 & 13,890 & 7,471 & 13,890 \\
\hline
\end{tabular}

$* * * \mathrm{p}<0.01, * * \mathrm{p}<0.05, * \mathrm{p}<0.1$. Each estimate is from a separate regression. The dependent variable in the first column is equal to one if the respondent reports ever having a pregnancy terminated, zero otherwise. The dependent variable in the second column is the number of years of education for a woman's husband. The dependent variable in the third column is the age of the husband subtracted by the woman's age, and the in the fourth column it is the years of schooling of the husband subtracted by the woman's years of schooling. The dependent variable is positive if the husband is older or has completed more years of schooling. There are fewer observations in column (2) because the data was only collected in the 1998, 2003, and 2008 waves of the survey. Inst $t_{c}$ is the probability of being treated by the 1985 reform, the variable ranges from 0 to 1 . The sample is restricted to only women in birth cohorts from 1950 to 1980. All regressions include a cubic for age, a three part cubic time trend (pre-treatment, transition, and post-treatment), and fixed effects for quarter of birth, ethnicity, and type of childhood residence. Each regression is weighted by sampling weights from the DHS, and standard errors are clustered at the birth cohort (year and quarter) level.

Table 11 - Reduced-form Estimates of the Effect of the Reform on Likelihood of Using Contraception Before First Birth

$\begin{array}{cccc}\text { Full Sample } & \begin{array}{c}\text { Less Than } 5 \text { Years } \\ \text { of Schooling }\end{array} \text { Attend College } & \begin{array}{c}\text { Treated Levels } \\ \text { of Schooling }\end{array}\end{array}$

(1) (2)

(3)

A. Three-part Time Trend

\begin{tabular}{|c|c|c|c|c|}
\hline Inst $_{c}$ & $\begin{array}{c}0.065 * * * \\
(0.010)\end{array}$ & $\begin{array}{c}0.022 \\
(0.026)\end{array}$ & $\begin{array}{l}-0.097 \\
(0.112)\end{array}$ & $\begin{array}{c}0.073 * * * \\
(0.013)\end{array}$ \\
\hline \multirow[b]{2}{*}{ Inst $_{c}$} & \multicolumn{4}{|c|}{ B. Quadratic Quarterly Time Trend } \\
\hline & $\begin{array}{c}0.031 * * * \\
(0.010)\end{array}$ & $\begin{array}{c}0.024 \\
(0.024)\end{array}$ & $\begin{array}{c}0.014 \\
(0.079)\end{array}$ & $\begin{array}{c}0.033 * * * \\
(0.011)\end{array}$ \\
\hline $\mathrm{N}$ & 19,631 & 2,988 & 970 & 12,862 \\
\hline \multicolumn{5}{|c|}{$\begin{array}{l}* * * \mathrm{p}<0.01, * * \mathrm{p}<0.05, * \mathrm{p}<0.1 \text {. Each estimate is from a separate regression. The dependent variable is equal to one for } \\
\text { women used modern contraception before having her first child, and zero otherwise. Inst } \mathrm{c}_{\mathrm{c}} \text { is the probability of being treated } \\
\text { by the } 1985 \text { reform, the variable ranges from } 0 \text { to } 1 \text {. The first column includes all women from } 1950 \text { to } 1980 \text { birth cohorts, } \\
\text { the second column includes only women who dropped out before completing five years of school, the third column only } \\
\text { includes women who attended college, and the fourth column includes only women who completed between seven years of } \\
\text { primary school and four years of secondary school. All regressions include a cubic for age, specified trend control, and } \\
\text { fixed effects for quarter of birth, ethnicity, and type of childhood residence. Each regression is weighted by sampling } \\
\text { weights from the DHS, and standard errors are clustered at the birth cohort (year and quarter) level. }\end{array}$} \\
\hline
\end{tabular}


Table 12 - Reduced-form Estimates of the Effect of the Reform on Being Tested for HIV/AIDS

\begin{tabular}{|c|c|c|c|c|}
\hline & $\begin{array}{c}\text { Full Sample } \\
\text { (1) }\end{array}$ & $\begin{array}{c}\text { Less Than } 5 \text { Years } \\
\text { of Schooling } \\
(2)\end{array}$ & $\begin{array}{c}\text { Attend College } \\
\text { (3) }\end{array}$ & $\begin{array}{c}\text { Treated Levels } \\
\text { of Schooling } \\
(4)\end{array}$ \\
\hline Inst $_{c}$ & $\begin{array}{l}0.109 * * * \\
(0.038)\end{array}$ & $\begin{array}{c}0.044 \\
(0.114)\end{array}$ & $\begin{array}{l}-0.034 \\
(0.119)\end{array}$ & $\begin{array}{c}0.162 * * * \\
(0.050)\end{array}$ \\
\hline $\mathrm{N}$ & 5,928 & 715 & 797 & 3,820 \\
\hline $\begin{array}{l}* * * \mathrm{p}<0 \\
\text { women } \\
\text { the } 200 \\
0 \text { to } 1.1 \\
\text { dropped } \\
\text { fourth c } \\
\text { school. }\end{array}$ & $\begin{array}{l}* \text { p }<0.1 \text {. Each } \\
\text { been tested for } 1 \\
\text { ads of the DHS. } \\
\text { includes all wo } \\
\text { npleting five yea } \\
\text { only women wl } \\
\text { include a cubic } \\
\text { hildhood resider }\end{array}$ & $\begin{array}{l}\text { from a separate regressio } \\
\text { S, and zero otherwise. Thi } \\
\text { e probability of being trea } \\
1950 \text { to } 1980 \text { birth cohor } \\
\text { ol, the third column only } \\
\text { ted between seven years } \\
\text { uadratic quarterly time tre } \\
\text { regression is weighted by }\end{array}$ & $\begin{array}{l}\text { The dependent varic } \\
\text { formation was only } \\
\text { l by the } 1985 \text { reform } \\
\text { the second column } \\
\text { ludes women who a } \\
\text { orimary school and } \mathrm{f} \\
\text { and fixed effects fo } \\
\text { mpling weights fron }\end{array}$ & $\begin{array}{l}\text { equal to one for } \\
\text { cted for women in } \\
\text { variable ranges from } \\
\text { les only women who } \\
\text { ed college, and the } \\
\text { ears of secondary } \\
\text { itter of birth, } \\
\text { DHS, and standard }\end{array}$ \\
\hline
\end{tabular}




\section{Appendix}

\section{a. Description of Three-part Trend}

When using the three part trend I assign each of the periods, pre, transition, and post, separate time trends. First, I create a count variable which identifies each individual's quarter of birth. The first quarter in the sample, 1950Q1, is equal to one, the second quarter to two, and the final quarter, 1980Q4, is equal to 124 . The beginning and end period of the trends match the previously described pre-form, transition, and post-reform periods of the data. The first quarter of the transition period is the $61^{\text {st }}$ quarter of the sample, and the first quarter of the post-reform period is the $89^{\text {th }}$ quarter. This variable is then used to define the beginning and end periods of the three trends. The trends are described by the following equations.

$$
\operatorname{TrPost}_{c}=\left\{\begin{array}{c}
b q_{c}-89 \text { if } b q_{c} \geq 89 \\
0 \text { if } b q_{c}<89
\end{array}\right.
$$

The variable defining an individual's birth quarter is $b q_{c}$. In the above specification the first quarter of the post-treatment period is equal to zero. The results are not sensitive to beginning the $\operatorname{TrPost}_{c}$ trend with the $89^{\text {th }}$ quarter being equal to one. The pre-treatment and transition trends are defined as follows.

$$
\begin{gathered}
\operatorname{TrPre}_{c}=\left\{\begin{array}{c}
\left|b q_{c}-61\right| \text { if } b q_{c} \leq 60 \\
0 \text { if } b q_{c}>60
\end{array}\right. \\
\operatorname{TrTran(sition)_{c}}=\left\{\begin{array}{c}
0 \text { if } b q_{c} \geq 89 \\
b q_{c}-60 \text { if } 60<b q_{c}<89 \\
0 \text { if } b q_{c} \leq 60
\end{array}\right.
\end{gathered}
$$


The absolute value used for the $\operatorname{TrPre}_{c}$ keeps the higher order values positive, but is unimportant. The $\operatorname{TrTransition}_{c}$ variable is currently increasing throughout the transition period, the results are insensitive to making this variable decreasing over the time period.

The equation using the three-part trend to estimate the effect of the reform uses the same set of covariates as described previously in the paper. The only difference is the trend $_{c}$ variable is replaced with the three separate variables shown above. The OLS equation can then be written as follows:

$$
y_{i c}=\alpha+\operatorname{yrschl}_{i c} \beta+\sum_{p=1}^{3} a g e_{i c}^{p} \pi_{p}+\sum_{n=1}^{N}\left[\operatorname{TrPr}_{c}^{n}+\operatorname{Tr}_{\operatorname{Tran}}^{n}+\operatorname{Tr}_{\operatorname{Post}}^{n}\right]+X_{i c} \theta+\varepsilon_{i c} .
$$


Table A1 - Reduced-form, Only Women with Age > 25: Age at First Intercourse/Marriage/Birth and Total Fertility, by Age

\begin{tabular}{|c|c|c|c|c|c|c|c|c|c|c|c|}
\hline \multicolumn{12}{|c|}{ A. First Intercourse by Age: } \\
\hline \multirow[b]{2}{*}{ Inst $_{c}$} & 15 & 16 & 17 & 18 & 19 & 20 & 21 & 22 & 23 & 24 & 25 \\
\hline & $\begin{array}{c}0.046 \\
(0.028)\end{array}$ & $\begin{array}{c}0.004 \\
(0.030)\end{array}$ & $\begin{array}{l}-0.032 \\
(0.035)\end{array}$ & $\begin{array}{l}-0.045 \\
(0.034)\end{array}$ & $\begin{array}{l}-0.057 * \\
(0.030)\end{array}$ & $\begin{array}{l}-0.037 \\
(0.025)\end{array}$ & $\begin{array}{c}-0.050 * * \\
(0.020)\end{array}$ & $\begin{array}{c}-0.050 * * * \\
(0.018)\end{array}$ & $\begin{array}{c}-0.052 * * * \\
(0.015)\end{array}$ & $\begin{array}{c}-0.044 * * * \\
(0.012)\end{array}$ & $\begin{array}{c}-0.028 * * * \\
(0.010)\end{array}$ \\
\hline $\mathrm{N}$ & 10,696 & 10,660 & 10,600 & 10,664 & 10,660 & 10,722 & 10,727 & 10,748 & 10,759 & 10,774 & 10,790 \\
\hline \multicolumn{12}{|c|}{ B. First Marriage by Age: } \\
\hline \multirow[b]{2}{*}{ Inst $_{c}$} & 15 & 16 & 17 & 18 & 19 & 20 & 21 & 22 & 23 & 24 & 25 \\
\hline & $\begin{array}{l}-0.014 \\
(0.024)\end{array}$ & $\begin{array}{l}-0.030 \\
(0.023)\end{array}$ & $\begin{array}{l}-0.034 \\
(0.025)\end{array}$ & $\begin{array}{l}-0.058^{*} \\
(0.032)\end{array}$ & $\begin{array}{l}-0.048 \\
(0.034)\end{array}$ & $\begin{array}{l}-0.049 \\
(0.033)\end{array}$ & $\begin{array}{c}-0.095 * * * \\
(0.031)\end{array}$ & $\begin{array}{l}-0.052^{*} \\
(0.030)\end{array}$ & $\begin{array}{l}-0.035 \\
(0.027)\end{array}$ & $\begin{array}{c}-0.053 * * \\
(0.024)\end{array}$ & $\begin{array}{c}-0.044 * * \\
(0.021)\end{array}$ \\
\hline $\mathrm{N}$ & 10,927 & 10,891 & 10,831 & 10,895 & 10,891 & 10,953 & 10,958 & 10,979 & 10,990 & 11,005 & 11,021 \\
\hline \multicolumn{12}{|c|}{ C. First Birth by Age: } \\
\hline \multirow[b]{2}{*}{ Inst $_{c}$} & 15 & 16 & 17 & 18 & 19 & 20 & 21 & 22 & 23 & 24 & 25 \\
\hline & $\begin{array}{c}0.006 \\
(0.018)\end{array}$ & $\begin{array}{c}0.007 \\
(0.027)\end{array}$ & $\begin{array}{l}-0.014 \\
(0.030)\end{array}$ & $\begin{array}{l}-0.017 \\
(0.034)\end{array}$ & $\begin{array}{l}-0.053 \\
(0.032)\end{array}$ & $\begin{array}{c}-0.088 * * * \\
(0.031)\end{array}$ & $\begin{array}{c}-0.090 \text { **** } \\
(0.033)\end{array}$ & $\begin{array}{c}-0.103 * * * \\
(0.035)\end{array}$ & $\begin{array}{c}-0.082 * * * \\
(0.030)\end{array}$ & $\begin{array}{c}-0.078 * * \\
(0.031)\end{array}$ & $\begin{array}{c}-0.076^{* * * *} \\
(0.023)\end{array}$ \\
\hline $\mathrm{N}$ & 10,927 & 10,891 & 10,831 & 10,895 & 10,891 & 10,953 & 10,958 & 10,979 & 10,990 & 11,005 & 11,021 \\
\hline \multicolumn{12}{|c|}{ D. Total Fertility by Age: } \\
\hline \multirow[b]{2}{*}{ Inst $_{c}$} & 15 & 16 & 17 & 18 & 19 & 20 & 21 & 22 & 23 & 24 & 25 \\
\hline & $\begin{array}{c}-0.002 \\
(0.024)\end{array}$ & $\begin{array}{c}0.015 \\
(0.033)\end{array}$ & $\begin{array}{l}-0.014 \\
(0.042)\end{array}$ & $\begin{array}{l}-0.008 \\
(0.053)\end{array}$ & $\begin{array}{l}-0.008 \\
(0.059)\end{array}$ & $\begin{array}{l}-0.103 \\
(0.071)\end{array}$ & $\begin{array}{l}-0.160^{*} \\
(0.085)\end{array}$ & $\begin{array}{c}-0.204 * * \\
(0.091)\end{array}$ & $\begin{array}{c}-0.251^{* *} \\
(0.098)\end{array}$ & $\begin{array}{c}-0.284 * * * \\
(0.108)\end{array}$ & $\begin{array}{c}-0.324 * * * \\
(0.108)\end{array}$ \\
\hline $\mathrm{N}$ & 10,927 & 10,891 & 10,831 & 10,895 & 10,891 & 10,953 & 10,958 & 10,979 & 10,990 & 11,005 & 11,021 \\
\hline
\end{tabular}


Table A2 - Reduced-form, Born After 1954: Age at First Intercourse/Marriage/Birth and Total Fertility, by Age

\begin{tabular}{|c|c|c|c|c|c|c|c|c|c|c|c|}
\hline \multicolumn{12}{|c|}{ A. First Intercourse by Age: } \\
\hline \multirow[b]{2}{*}{ Inst $_{\mathrm{c}}$} & 15 & 16 & 17 & 18 & 19 & 20 & 21 & 22 & 23 & 24 & 25 \\
\hline & $\begin{array}{l}0.038 * \\
(0.022)\end{array}$ & $\begin{array}{c}0.000 \\
(0.023)\end{array}$ & $\begin{array}{c}0.009 \\
(0.026)\end{array}$ & $\begin{array}{c}-0.018 \\
(0.028)\end{array}$ & $\begin{array}{l}-0.012 \\
(0.024)\end{array}$ & $\begin{array}{c}0.003 \\
(0.020)\end{array}$ & $\begin{array}{l}-0.009 \\
(0.016)\end{array}$ & $\begin{array}{l}-0.006 \\
(0.015)\end{array}$ & $\begin{array}{c}-0.036 * * * \\
(0.012)\end{array}$ & $\begin{array}{c}-0.034 * * * \\
(0.011)\end{array}$ & $\begin{array}{c}-0.024 * * \\
(0.009)\end{array}$ \\
\hline $\mathrm{N}$ & 17,698 & 17,113 & 16,368 & 15,548 & 14,711 & 13,893 & 13,245 & 12,468 & 11,540 & 10,649 & 9,840 \\
\hline \multicolumn{12}{|c|}{ B. First Marriage by Age: } \\
\hline \multirow[b]{2}{*}{ Inst $_{c}$} & 15 & 16 & 17 & 18 & 19 & 20 & 21 & 22 & 23 & 24 & 25 \\
\hline & $\begin{array}{c}0.022 \\
(0.016)\end{array}$ & $\begin{array}{l}-0.010 \\
(0.019)\end{array}$ & $\begin{array}{l}-0.014 \\
(0.020)\end{array}$ & $\begin{array}{c}-0.052^{* * *} \\
(0.023)\end{array}$ & $\begin{array}{c}-0.052 * * \\
(0.023)\end{array}$ & $\begin{array}{c}-0.052 * * \\
(0.025)\end{array}$ & $\begin{array}{c}-0.058 * * \\
(0.024)\end{array}$ & $\begin{array}{l}-0.013 \\
(0.025)\end{array}$ & $\begin{array}{l}-0.013 \\
(0.027)\end{array}$ & $\begin{array}{l}-0.033 \\
(0.024)\end{array}$ & $\begin{array}{c}-0.042 * \\
(0.022)\end{array}$ \\
\hline $\mathrm{N}$ & 18,021 & 17,432 & 16,677 & 15,851 & 15,003 & 14,156 & 13,497 & 12,708 & 11,759 & 10,839 & 10,010 \\
\hline
\end{tabular}

\begin{tabular}{|c|c|c|c|c|c|c|c|c|c|c|c|}
\hline \multicolumn{12}{|c|}{ C. First Birth by Age: } \\
\hline & 15 & 16 & 17 & 18 & 19 & 20 & 21 & 22 & 23 & 24 & 25 \\
\hline Inst $_{c}$ & $\begin{array}{c}0.015 \\
(0.015)\end{array}$ & $\begin{array}{c}0.020 \\
(0.020)\end{array}$ & $\begin{array}{c}0.004 \\
(0.021)\end{array}$ & $\begin{array}{l}-0.014 \\
(0.025)\end{array}$ & $\begin{array}{l}-0.038 \\
(0.025)\end{array}$ & $\begin{array}{c}-0.068 * * * \\
(0.023)\end{array}$ & $\begin{array}{l}-0.054 * \\
(0.028)\end{array}$ & $\begin{array}{l}-0.050^{*} \\
(0.029)\end{array}$ & $\begin{array}{c}-0.059^{* *} \\
(0.026)\end{array}$ & $\begin{array}{c}-0.071 * * \\
(0.029)\end{array}$ & $\begin{array}{c}-0.079 * * * \\
(0.023)\end{array}$ \\
\hline $\mathrm{N}$ & 18,021 & 17,432 & 16,677 & 15,851 & 15,003 & 14,156 & 13,497 & 12,708 & 11,759 & 10,839 & 10,010 \\
\hline
\end{tabular}

D. Total Fertility by Age:

\begin{tabular}{|c|c|c|c|c|c|c|c|c|c|c|c|}
\hline \multirow{3}{*}{ Inst $_{\mathrm{c}}$} & 15 & 16 & 17 & 18 & 19 & 20 & 21 & 22 & 23 & 24 & 25 \\
\hline & 0.012 & 0.032 & 0.022 & 0.011 & -0.005 & -0.082 & $-0.136 * *$ & $-0.135^{*}$ & $-0.187 * *$ & $-0.251 * *$ & $-0.270 * *$ \\
\hline & $(0.019)$ & $(0.028)$ & $(0.032)$ & $(0.044)$ & $(0.048)$ & $(0.054)$ & $(0.068)$ & $(0.077)$ & $(0.089)$ & $(0.102)$ & (0.109) \\
\hline & 18,021 & 17,432 & 16,677 & 15,851 & 15,003 & 14,156 & 13,497 & 12,708 & 11,759 & 10,839 & 10,010 \\
\hline
\end{tabular}

*** $\mathrm{p}<0.01, * * \mathrm{p}<0.05, * \mathrm{p}<0.1$. Each estimate is from a separate regression. In panels A, B, and $\mathrm{C}$ the dependent variable is equal to one if the event occurred by the given age, in panel

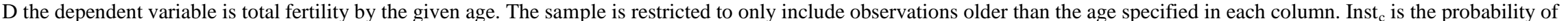
being treated by the 1985 reform, the variable ranges from 0 to 1 . Sample includes women in birth cohorts from 1955 to 1980 . All regressions include a cubic for age, a quadratic quarterly time trend, the number of students enrolled in grade one during the respondent's age 6 year, and fixed effects for quarter of birth, ethnicity, and type of childhood residence. Each regression is weighted by sampling weights from the DHS, and standard errors are clustered at the birth cohort (year and quarter) level. 
Table A3 - Reduced-form, Annual Instrument Calculated Using Enrollment Data: Age at First Intercourse/Marriage/Birth and Total Fertility, by Age

\begin{tabular}{|c|c|c|c|c|c|c|c|c|c|c|c|}
\hline \multicolumn{12}{|c|}{ A. First Intercourse by Age: } \\
\hline \multicolumn{12}{|c|}{$\begin{array}{l}\text { A. First Intercourse by Age: } \\
15\end{array}$} \\
\hline Annual & 0.019 & -0.023 & -0.027 & -0.038 & -0.037 & -0.014 & $-0.023 * *$ & -0.016 & $-0.043 * * *$ & $-0.038 * * *$ & $-0.028 * * *$ \\
\hline Inst $_{\text {by }}$ & $(0.028)$ & $(0.028)$ & $(0.033)$ & $(0.030)$ & $(0.024)$ & $(0.015)$ & $(0.011)$ & $(0.014)$ & $(0.007)$ & $(0.009)$ & $(0.010)$ \\
\hline $\mathrm{N}$ & 18,645 & 18,059 & 17,308 & 16,495 & 15,657 & 14,842 & 14,192 & 13,417 & 12,489 & 11,598 & 10,790 \\
\hline \multicolumn{12}{|c|}{ B. First Marriage by Age: } \\
\hline & 15 & 16 & 17 & 18 & 19 & 20 & 21 & 22 & 23 & 24 & 25 \\
\hline Annual & 0.009 & -0.021 & -0.027 & $-0.063 * * *$ & $-0.061 * *$ & $-0.065 * *$ & $-0.069 * * *$ & -0.017 & -0.022 & $-0.037 * * *$ & $-0.045^{* *}$ \\
\hline Inst $_{\text {by }}$ & $(0.017)$ & $(0.018)$ & $(0.028)$ & $(0.022)$ & $(0.024)$ & $(0.024)$ & $(0.015)$ & $(0.018)$ & $(0.021)$ & $(0.013)$ & $(0.019)$ \\
\hline $\mathrm{N}$ & 19,029 & 18,439 & 17,678 & 16,859 & 16,010 & 15,166 & 14,505 & 13,718 & 12,769 & 11,849 & 11,021 \\
\hline
\end{tabular}

\begin{tabular}{|c|c|c|c|c|c|c|c|c|c|c|c|}
\hline \multicolumn{12}{|c|}{ C. First Birth by Age: } \\
\hline & 15 & 16 & 17 & 18 & 19 & 20 & 21 & 22 & 23 & 24 & 25 \\
\hline $\begin{array}{l}\text { Annual } \\
\text { Inst }_{\text {by }}\end{array}$ & $\begin{array}{c}0.008 \\
(0.017)\end{array}$ & $\begin{array}{c}0.008 \\
(0.026)\end{array}$ & $\begin{array}{l}-0.011 \\
(0.025)\end{array}$ & $\begin{array}{l}-0.027 \\
(0.033)\end{array}$ & $\begin{array}{l}-0.057 * \\
(0.029)\end{array}$ & $\begin{array}{c}-0.084 * * * \\
(0.016)\end{array}$ & $\begin{array}{c}-0.068 * * * \\
(0.021)\end{array}$ & $\begin{array}{c}-0.060 * * * \\
(0.017)\end{array}$ & $\begin{array}{c}-0.068 * * * \\
(0.018)\end{array}$ & $\begin{array}{c}-0.073 * * * \\
(0.017)\end{array}$ & $\begin{array}{c}-0.077 * * * \\
(0.018)\end{array}$ \\
\hline $\mathrm{N}$ & 19,029 & 18,439 & 17,678 & 16,859 & 16,010 & 15,166 & 14,505 & 13,718 & 12,769 & 11,849 & 11,021 \\
\hline
\end{tabular}

D. Total Fertility by Age:

\begin{tabular}{|c|c|c|c|c|c|c|c|c|c|c|c|}
\hline & 15 & 16 & 17 & 18 & 19 & 20 & 21 & 22 & 23 & 24 & 25 \\
\hline Annual & 0.006 & 0.017 & 0.002 & -0.016 & -0.032 & $-0.115^{*}$ & $-0.162 * *$ & $-0.158 * * *$ & $-0.236^{* * *}$ & $-0.294 * * *$ & $-0.328 * * *$ \\
\hline Inst $_{\text {by }}$ & $(0.021)$ & $(0.035)$ & (0.039) & $(0.055)$ & $(0.060)$ & $(0.057)$ & $(0.072)$ & $(0.056)$ & $(0.072)$ & (0.088) & $(0.100)$ \\
\hline $\mathrm{N}$ & 19,029 & 18,439 & 17,678 & 16,859 & 16,010 & 15,166 & 14,505 & 13,718 & 12,769 & 11,849 & 11,021 \\
\hline
\end{tabular}

$* * * \mathrm{p}<0.01, * * \mathrm{p}<0.05, * \mathrm{p}<0.1$. Each estimate is from a separate regression. In panels A, B, and C the dependent variable is equal to one if the event occurred by the given age, in panel

$\mathrm{D}$ the dependent variable is total fertility by the given age. The sample is restricted to only include observations older than the age specified in each column. Annual Inst $\mathrm{by}_{\mathrm{by}}$ is the

probability of being treated by the 1985 reform without adjusting for quarter of birth, the variable ranges from 0 to 1 . Sample includes women in birth cohorts from 1950 to 1980 . All

regressions include a cubic for age, a quadratic quarterly time trend, and fixed effects for quarter of birth, ethnicity, and type of childhood residence. Each regression is weighted by

sampling weights from the DHS, and standard errors are clustered at the birth year level. 
Table A4 - Reduced-form, Using Annual Alternative Instrument: Age at First Intercourse/Marriage/Birth and Total Fertility, by Age

\begin{tabular}{|c|c|c|c|c|c|c|c|c|c|c|c|}
\hline \multicolumn{12}{|c|}{ A. First Intercourse by Age: } \\
\hline & 15 & 16 & 17 & 18 & 19 & 20 & 21 & 22 & 23 & 24 & 25 \\
\hline $\begin{array}{l}\text { Alternative } \\
\text { Annual Inst }{ }_{\text {by }}\end{array}$ & $\begin{array}{c}0.005 \\
(0.028)\end{array}$ & $\begin{array}{l}-0.037 \\
(0.029)\end{array}$ & $\begin{array}{l}-0.045 \\
(0.033)\end{array}$ & $\begin{array}{l}-0.055^{*} \\
(0.031)\end{array}$ & $\begin{array}{c}-0.051 * * \\
(0.024)\end{array}$ & $\begin{array}{l}-0.018 \\
(0.017)\end{array}$ & $\begin{array}{c}-0.030 * * \\
(0.013)\end{array}$ & $\begin{array}{l}-0.020 \\
(0.017)\end{array}$ & $\begin{array}{c}-0.050 * * * \\
(0.008)\end{array}$ & $\begin{array}{c}-0.041 * * * \\
(0.011)\end{array}$ & $\begin{array}{c}-0.033 * * * \\
(0.011)\end{array}$ \\
\hline $\mathrm{N}$ & 18,645 & 18,059 & 17,308 & 16,495 & 15,657 & 14,842 & 14,192 & 13,417 & 12,489 & 11,598 & 10,790 \\
\hline
\end{tabular}

\begin{tabular}{|c|c|c|c|c|c|c|c|c|c|c|c|}
\hline \multicolumn{12}{|c|}{ B. First Marriage by Age: } \\
\hline & 15 & 16 & 17 & 18 & 19 & 20 & 21 & 22 & 23 & 24 & 25 \\
\hline $\begin{array}{l}\text { Alternative } \\
\text { Annual Inst }\end{array}$ & $\begin{array}{c}0.004 \\
(0.019)\end{array}$ & $\begin{array}{l}-0.028 \\
(0.019)\end{array}$ & $\begin{array}{l}-0.032 \\
(0.032)\end{array}$ & $\begin{array}{c}-0.072 * * * \\
(0.023)\end{array}$ & $\begin{array}{c}-0.066^{* *} \\
(0.026)\end{array}$ & $\begin{array}{c}-0.079 * * * \\
(0.027)\end{array}$ & $\begin{array}{c}-0.077 * * * \\
(0.017)\end{array}$ & $\begin{array}{l}-0.018 \\
(0.019)\end{array}$ & $\begin{array}{l}-0.021 \\
(0.024)\end{array}$ & $\begin{array}{c}-0.042 * * * \\
(0.012)\end{array}$ & $\begin{array}{c}-0.055^{* *} \\
(0.023)\end{array}$ \\
\hline $\mathrm{N}$ & 19,029 & 18,439 & 17,678 & 16,859 & 16,010 & 15,166 & 14,505 & 13,718 & 12,769 & 11,849 & 11,021 \\
\hline
\end{tabular}

\begin{tabular}{|c|c|c|c|c|c|c|c|c|c|c|c|}
\hline \multicolumn{12}{|c|}{ C. First Birth by Age: } \\
\hline & 15 & 16 & 17 & 18 & 19 & 20 & 21 & 22 & 23 & 24 & 25 \\
\hline $\begin{array}{l}\text { Alternative } \\
\text { Annual Inst }\end{array}$ & $\begin{array}{l}0.005 \\
(0.016)\end{array}$ & $\begin{array}{l}-0.004 \\
(0.027)\end{array}$ & $\begin{array}{l}-0.018 \\
(0.028)\end{array}$ & $\begin{array}{l}-0.041 \\
(0.038)\end{array}$ & $\begin{array}{c}-0.072 * * \\
(0.035)\end{array}$ & $\begin{array}{c}-0.093 * * * \\
(0.018)\end{array}$ & $\begin{array}{c}-0.077 * * * \\
(0.024)\end{array}$ & $\begin{array}{c}-0.064 * * * \\
(0.018)\end{array}$ & $\begin{array}{c}-0.065^{* * * *} \\
(0.020)\end{array}$ & $\begin{array}{c}-0.072 * * * \\
(0.018)\end{array}$ & $\begin{array}{c}-0.086^{* * * *} \\
(0.021)\end{array}$ \\
\hline $\mathrm{N}$ & 19,029 & 18,439 & 17,678 & 16,859 & 16,010 & 15,166 & 14,505 & 13,718 & 12,769 & 11,849 & 11,021 \\
\hline
\end{tabular}

D. Total Fertility by Age:

\begin{tabular}{lcccccccccccc} 
& 15 & 16 & 17 & 18 & 19 & 20 & 21 & 22 & 23 & 24 \\
\cline { 2 - 7 } & Alternative & 0.003 & 0.006 & -0.008 & -0.033 & -0.041 & $-0.130^{* *}$ & $-0.194^{* *}$ & $-0.176^{* * *}$ & $-0.247^{* * *}$ & $-0.300^{* * *}$ & $-0.321^{* * *}$ \\
Annual Inst by & $(0.021)$ & $(0.037)$ & $(0.040)$ & $(0.056)$ & $(0.070)$ & $(0.059)$ & $(0.079)$ & $(0.055)$ & $(0.068)$ & $(0.084)$ & $(0.090)$ \\
$\mathrm{N}$ & & & & & & & & & & & \\
$\mathrm{N}$ & 19,029 & 18,439 & 17,678 & 16,859 & 16,010 & 15,166 & 14,505 & 13,718 & 12,769 & 11,849 & 11,021 \\
\hline
\end{tabular}

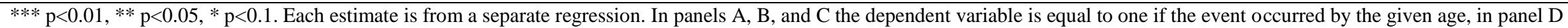

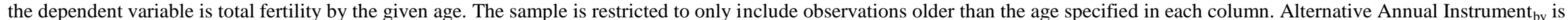
calculated without using enrollment data, as outlined in the text, or the quarter of birth adjustment. It is the estimated probability of being treated by the 1985 reform, the variable ranges from 0 to 1. Sample includes women in birth cohorts from 1950 to 1980. All regressions include a cubic for age, a quadratic quarterly time trend, and fixed effects for quarter of birth, ethnicity, and type of childhood residence. Each regression is weighted by sampling weights from the DHS, and standard errors are clustered at the birth year level. 
Table A5 - Reduced-form, Including Women with Imputed Month/Year of Birth: Age at First Intercourse/Marriage/Birth and Total Fertility, by Age

\begin{tabular}{|c|c|c|c|c|c|c|c|c|c|c|c|}
\hline \multicolumn{12}{|c|}{ A. First Intercourse by Age: } \\
\hline Inst $_{c}$ & $\begin{array}{c}0.030 \\
(0.021)\end{array}$ & $\begin{array}{c}0.001 \\
(0.022)\end{array}$ & $\begin{array}{l}-0.017 \\
(0.024)\end{array}$ & $\begin{array}{l}-0.029 \\
(0.025)\end{array}$ & $\begin{array}{l}-0.019 \\
(0.021)\end{array}$ & $\begin{array}{l}-0.010 \\
(0.017)\end{array}$ & $\begin{array}{l}-0.020 \\
(0.014)\end{array}$ & $\begin{array}{l}-0.009 \\
(0.012)\end{array}$ & $\begin{array}{c}-0.026^{* *} \\
(0.011)\end{array}$ & $\begin{array}{l}-0.022 * \\
(0.011)\end{array}$ & $\begin{array}{l}-0.014 \\
(0.011)\end{array}$ \\
\hline
\end{tabular}

\begin{tabular}{|c|c|c|c|c|c|c|c|c|c|c|c|}
\hline \multicolumn{12}{|c|}{ B. First Marriage by Age: } \\
\hline & 15 & 16 & 17 & 18 & 19 & 20 & 21 & 22 & 23 & 24 & 25 \\
\hline Inst $_{\mathrm{c}}$ & $\begin{array}{c}0.014 \\
(0.013)\end{array}$ & $\begin{array}{l}-0.007 \\
(0.015)\end{array}$ & $\begin{array}{l}-0.012 \\
(0.019)\end{array}$ & $\begin{array}{c}-0.038^{* *} \\
(0.019)\end{array}$ & $\begin{array}{c}-0.046 * * \\
(0.020)\end{array}$ & $\begin{array}{c}-0.053 * * * \\
(0.020)\end{array}$ & $\begin{array}{c}-0.054 * * * \\
(0.018)\end{array}$ & $\begin{array}{c}-0.002 \\
(0.019)\end{array}$ & $\begin{array}{c}0.000 \\
(0.021)\end{array}$ & $\begin{array}{l}-0.021 \\
(0.018)\end{array}$ & $\begin{array}{l}-0.027 \\
(0.017)\end{array}$ \\
\hline $\mathrm{N}$ & 27,459 & 26,692 & 25,773 & 24,814 & 23,814 & 22,779 & 21,992 & 21,038 & 19,854 & 18,712 & 17,590 \\
\hline
\end{tabular}

\begin{tabular}{lcccccccccccc}
\hline \multicolumn{2}{l}{ C. First Birth by Age: } & 15 & 16 & 17 & 18 & 19 & 20 & 21 & 22 & 23 & 24 \\
Inst $_{\mathrm{c}}$ & $0.026^{* *}$ & 0.025 & 0.008 & -0.006 & -0.029 & $-0.053^{* *}$ & $-0.049^{*}$ & $-0.043^{*}$ & $-0.044^{* *}$ & $-0.041^{*}$ & $-0.045^{* *}$ \\
& $(0.013)$ & $(0.018)$ & $(0.019)$ & $(0.023)$ & $(0.025)$ & $(0.023)$ & $(0.025)$ & $(0.024)$ & $(0.022)$ & $(0.024)$ & $(0.020)$ \\
& & & & & & & & & & & & \\
$\mathrm{N}$ & 27,459 & 26,692 & 25,773 & 24,814 & 23,814 & 22,779 & 21,992 & 21,038 & 19,854 & 18,712 & 17,590
\end{tabular}

D. Total Fertility by Age:

\begin{tabular}{|c|c|c|c|c|c|c|c|c|c|c|c|}
\hline & 15 & 16 & 17 & 18 & 19 & 20 & 21 & 22 & 23 & 24 & 25 \\
\hline Inst $_{c}$ & $\begin{array}{c}0.037 * * \\
(0.015)\end{array}$ & $\begin{array}{c}0.053 * * \\
(0.024)\end{array}$ & $\begin{array}{c}0.039 \\
(0.028)\end{array}$ & $\begin{array}{c}0.040 \\
(0.038)\end{array}$ & $\begin{array}{c}0.028 \\
(0.046)\end{array}$ & $\begin{array}{c}-0.042 \\
(0.054)\end{array}$ & $\begin{array}{c}-0.088 \\
(0.061)\end{array}$ & $\begin{array}{c}-0.084 \\
(0.068)\end{array}$ & $\begin{array}{c}-0.133 \\
(0.082)\end{array}$ & $\begin{array}{l}-0.173 * \\
(0.092)\end{array}$ & $\begin{array}{c}-0.202^{* * *} \\
(0.101)\end{array}$ \\
\hline $\mathrm{N}$ & 27,459 & 26,692 & 25,773 & 24,814 & 23,814 & 22,779 & 21,992 & 21,038 & 19,854 & 18,712 & 17,590 \\
\hline
\end{tabular}

$* * * \mathrm{p}<0.01, * * \mathrm{p}<0.05, * \mathrm{p}<0.1$. Each estimate is from a separate regression. Each estimate is from a separate regression. In panels $\mathrm{A}, \mathrm{B}$, and $\mathrm{C}$ the dependent variable is equal to one if the event occurred by the given age, in panel D the dependent variable is total fertility by the given age. The sample is restricted to only include observations older than the age specified in each column. Inst is the probability of being treated by the 1985 reform, the variable ranges from 0 to 1 . Sample includes women in birth cohorts from 1950 to 1980 . The sample includes respondents who cannot specify their birth month or year, these data are imputed for them by the DHS. All regressions include a cubic for age, a quadratic quarterly time trend, and fixed effects for quarter of birth, ethnicity, and type of childhood residence. Each regression is weighted by sampling weights from the DHS, and standard errors are clustered at the birth cohort (year and quarter) level. 
Table A6 - Estimates Using Alternative Trends: Age at First Intercourse/Marriage and Total Fertility

\begin{tabular}{|c|c|c|c|c|c|c|c|c|c|c|c|c|}
\hline \multicolumn{4}{|c|}{ A. Quarterly Trend } & \multicolumn{3}{|c|}{ First Intercourse by Age: } & \multicolumn{3}{|c|}{ First Marriage by Age: } & \multicolumn{3}{|c|}{ Total Fertility by Age: } \\
\hline & YearsSchl & AtLeast8 & Education8 & 15 & 20 & 25 & 15 & 20 & 25 & 15 & 20 & 25 \\
\hline Linear & $\begin{array}{c}0.308 \\
(0.228)\end{array}$ & $\begin{array}{c}0.202 * * * \\
(0.025)\end{array}$ & $\begin{array}{c}0.276^{* * * *} \\
(0.014)\end{array}$ & $\begin{array}{c}0.028 \\
(0.021)\end{array}$ & $\begin{array}{l}-0.013 \\
(0.017)\end{array}$ & $\begin{array}{c}-0.025 * * * \\
(0.007)\end{array}$ & $\begin{array}{c}0.024 \\
(0.016)\end{array}$ & $\begin{array}{l}-0.023 \\
(0.023)\end{array}$ & $\begin{array}{l}-0.010 \\
(0.018)\end{array}$ & $\begin{array}{c}0.014 \\
(0.017)\end{array}$ & $\begin{array}{l}-0.077 \\
(0.050)\end{array}$ & $\begin{array}{c}-0.146^{*} \\
(0.088)\end{array}$ \\
\hline Quadratic & $\begin{array}{c}0.740 * * * \\
(0.153)\end{array}$ & $\begin{array}{c}0.233 * * * \\
(0.023)\end{array}$ & $\begin{array}{c}0.274 * * * \\
(0.016)\end{array}$ & $\begin{array}{c}0.020 \\
(0.020)\end{array}$ & $\begin{array}{l}-0.015 \\
(0.020)\end{array}$ & $\begin{array}{c}-0.028 * * * \\
(0.010)\end{array}$ & $\begin{array}{c}0.010 \\
(0.015)\end{array}$ & $\begin{array}{c}-0.063 * * * \\
(0.024)\end{array}$ & $\begin{array}{c}-0.044 * * \\
(0.021)\end{array}$ & $\begin{array}{c}0.007 \\
(0.016)\end{array}$ & $\begin{array}{c}-0.113 * * \\
(0.050)\end{array}$ & $\begin{array}{c}-0.324 * * * \\
(0.108)\end{array}$ \\
\hline \multicolumn{4}{|c|}{ B. Three-part Trend } & \multicolumn{3}{|c|}{ First Intercourse by Age: } & \multicolumn{2}{|c|}{ First Marriage by Age: } & & \multicolumn{3}{|c|}{ Total Fertility by Age: } \\
\hline & YearsSchl & AtLeast8 & Education8 & 15 & 20 & 25 & 15 & 20 & 25 & 15 & 20 & 25 \\
\hline Linear & $\begin{array}{c}1.309 \\
(0.102)\end{array}$ & $\begin{array}{c}0.260 * * * \\
(0.016)\end{array}$ & $\begin{array}{c}0.269 * * * \\
(0.013)\end{array}$ & $\begin{array}{c}-0.044 * * * \\
(0.015)\end{array}$ & $\begin{array}{c}-0.050^{* * *} \\
(0.013)\end{array}$ & $\begin{array}{c}-0.029 * * * \\
(0.007)\end{array}$ & $\begin{array}{c}-0.027 * * \\
(0.011)\end{array}$ & $\begin{array}{c}-0.084 * * * \\
(0.016)\end{array}$ & $\begin{array}{c}-0.054 * * * \\
(0.016)\end{array}$ & $\begin{array}{c}-0.026^{* *} \\
(0.011)\end{array}$ & $\begin{array}{c}-0.224 * * * \\
(0.031)\end{array}$ & $\begin{array}{c}-0.447 * * * \\
(0.051)\end{array}$ \\
\hline Quadratic & $\begin{array}{c}1.279 * * * \\
(0.154)\end{array}$ & $\begin{array}{c}0.306^{* * *} \\
(0.022)\end{array}$ & $\begin{array}{c}0.304 * * * \\
(0.019)\end{array}$ & $\begin{array}{l}-0.017 \\
(0.019)\end{array}$ & $\begin{array}{l}-0.022 \\
(0.019)\end{array}$ & $\begin{array}{c}-0.031 * * * \\
(0.011)\end{array}$ & $\begin{array}{c}0.004 \\
(0.016)\end{array}$ & $\begin{array}{c}-0.086^{* * *} \\
(0.020)\end{array}$ & $\begin{array}{c}-0.078 * * * \\
(0.022)\end{array}$ & $\begin{array}{l}-0.007 \\
(0.015)\end{array}$ & $\begin{array}{c}-0.153 * * * \\
(0.037)\end{array}$ & $\begin{array}{c}-0.452 * * * \\
(0.072)\end{array}$ \\
\hline Cubic & $\begin{array}{c}1.644 * * * \\
(0.178)\end{array}$ & $\begin{array}{c}0.335^{* * *} * \\
(0.024)\end{array}$ & $\begin{array}{c}0.286 * * * \\
(0.024)\end{array}$ & $\begin{array}{c}-0.063 * * * \\
(0.022)\end{array}$ & $\begin{array}{l}-0.033 \\
(0.024)\end{array}$ & $\begin{array}{c}-0.033 * * * \\
(0.012)\end{array}$ & $\begin{array}{l}-0.031 \\
(0.020)\end{array}$ & $\begin{array}{c}-0.112 * * * \\
(0.023)\end{array}$ & $\begin{array}{c}-0.084 * * * \\
(0.026)\end{array}$ & $\begin{array}{l}-0.028 \\
(0.018)\end{array}$ & $\begin{array}{c}-0.196 * * * \\
(0.047)\end{array}$ & $\begin{array}{c}-0.037 * * * \\
(0.093)\end{array}$ \\
\hline
\end{tabular}

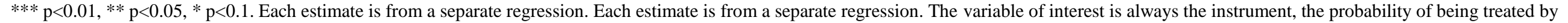

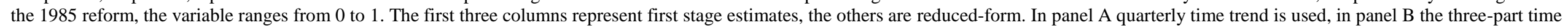

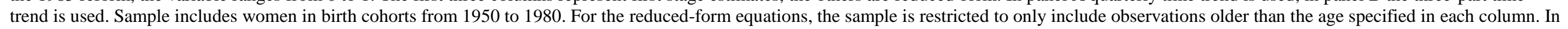

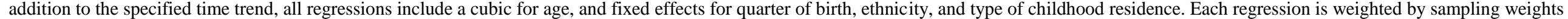
from the DHS, and standard errors are clustered at the birth cohort (year and quarter) level. 
Table A7 - Reduced From: Age at First Intercourse/Marriage/Birth and Total Fertility, by Age. Using the Cubic Three-part Time Trend

\begin{tabular}{|c|c|c|c|c|c|c|c|c|c|c|c|}
\hline \multicolumn{12}{|c|}{ A. First Intercourse by Age: } \\
\hline \multirow[b]{2}{*}{ Inst $_{\mathrm{c}}$} & 15 & 16 & 17 & 18 & 19 & 20 & 21 & 22 & 23 & 24 & 25 \\
\hline & $\begin{array}{c}-0.063 * * * \\
(0.022)\end{array}$ & $\begin{array}{c}-0.075 * * \\
(0.030)\end{array}$ & $\begin{array}{c}-0.070 * * \\
(0.034)\end{array}$ & $\begin{array}{c}-0.069 * * \\
(0.031)\end{array}$ & $\begin{array}{c}-0.078 * * * \\
(0.027)\end{array}$ & $\begin{array}{l}-0.033 \\
(0.024)\end{array}$ & $\begin{array}{l}-0.021 \\
(0.022)\end{array}$ & $\begin{array}{c}-0.050 * * \\
(0.020)\end{array}$ & $\begin{array}{c}-0.045^{* *} \\
(0.018)\end{array}$ & $\begin{array}{c}-0.045 * * * \\
(0.015)\end{array}$ & $\begin{array}{c}-0.033 * * * \\
(0.012)\end{array}$ \\
\hline $\mathrm{N}$ & 18,645 & 18,059 & 17,308 & 16,495 & 15,657 & 14,842 & 14,192 & 13,417 & 12,489 & 11,598 & 10,790 \\
\hline \multicolumn{12}{|c|}{ B. First Marriage by Age: } \\
\hline \multirow[b]{2}{*}{ Inst $_{\mathrm{c}}$} & 15 & 16 & 17 & 18 & 19 & 20 & 21 & 22 & 23 & 24 & 25 \\
\hline & $\begin{array}{l}-0.031 \\
(0.020)\end{array}$ & $\begin{array}{c}-0.070 * * * \\
(0.021)\end{array}$ & $\begin{array}{c}-0.055^{* *} \\
(0.024)\end{array}$ & $\begin{array}{c}-0.122 * * * \\
(0.025)\end{array}$ & $\begin{array}{c}-0.117 * * * \\
(0.026)\end{array}$ & $\begin{array}{c}-0.112 * * * \\
(0.023)\end{array}$ & $\begin{array}{c}-0.074 * * * \\
(0.025)\end{array}$ & $\begin{array}{c}-0.079 * * * \\
(0.026)\end{array}$ & $\begin{array}{c}-0.072 * * \\
(0.033)\end{array}$ & $\begin{array}{l}-0.064^{*} \\
(0.036)\end{array}$ & $\begin{array}{c}-0.084 * * * \\
(0.026)\end{array}$ \\
\hline $\mathrm{N}$ & 19,029 & 18,439 & 17,678 & 16,859 & 16,010 & 15,166 & 14,505 & 13,718 & 12,769 & 11,849 & 11,021 \\
\hline \multicolumn{12}{|c|}{ C. First Birth by Age: } \\
\hline \multirow[b]{2}{*}{ Inst $_{c}$} & 15 & 16 & 17 & 18 & 19 & 20 & 21 & 22 & 23 & 24 & 25 \\
\hline & $\begin{array}{l}-0.024 \\
(0.017)\end{array}$ & $\begin{array}{l}-0.034 \\
(0.023)\end{array}$ & $\begin{array}{c}-0.061 * * \\
(0.025)\end{array}$ & $\begin{array}{l}-0.042 \\
(0.031)\end{array}$ & $\begin{array}{c}-0.070^{* *} \\
(0.031)\end{array}$ & $\begin{array}{c}-0.115^{* * * *} \\
(0.030)\end{array}$ & $\begin{array}{c}-0.077 * \\
(0.042)\end{array}$ & $\begin{array}{l}-0.062 \\
(0.038)\end{array}$ & $\begin{array}{c}-0.076^{* *} \\
(0.033)\end{array}$ & $\begin{array}{l}-0.056 \\
(0.036)\end{array}$ & $\begin{array}{l}-0.059 \\
(0.037)\end{array}$ \\
\hline $\mathrm{N}$ & 19,029 & 18,439 & 17,678 & 16,859 & 16,010 & 15,166 & 14,505 & 13,718 & 12,769 & 11,849 & 11,021 \\
\hline \multicolumn{12}{|c|}{ D. Total Fertility by Age: } \\
\hline \multirow[b]{2}{*}{ Inst $_{\mathrm{c}}$} & 15 & 16 & 17 & 18 & 19 & 20 & 21 & 22 & 23 & 24 & 25 \\
\hline & $\begin{array}{l}-0.028 \\
(0.018)\end{array}$ & $\begin{array}{c}-0.045^{*} \\
(0.027)\end{array}$ & $\begin{array}{c}-0.074 * * * \\
(0.027)\end{array}$ & $\begin{array}{c}-0.078^{*} \\
(0.042)\end{array}$ & $\begin{array}{c}-0.089^{*} \\
(0.049)\end{array}$ & $\begin{array}{c}-0.196^{* * * *} \\
(0.047)\end{array}$ & $\begin{array}{c}-0.259^{* * *} * \\
(0.068)\end{array}$ & $\begin{array}{c}-0.334 * * * \\
(0.060)\end{array}$ & $\begin{array}{c}-0.393 * * * \\
(0.067)\end{array}$ & $\begin{array}{c}-0.384 * * * \\
(0.079)\end{array}$ & $\begin{array}{c}-0.367 * * * \\
(0.093)\end{array}$ \\
\hline $\mathrm{N}$ & 19,029 & 18,439 & 17,678 & 16,859 & 16,010 & 15,166 & 14,505 & 13,718 & 12,769 & 11,849 & 11,021 \\
\hline
\end{tabular}

$* * * \mathrm{p}<0.01, * * \mathrm{p}<0.05, * \mathrm{p}<0.1$. Each estimate is from a separate regression. Each estimate is from a separate regression. In panels A, B, and C the dependent variable is equal to one if the event occurred by the given age, in panel D the dependent variable is total fertility by the given age. The sample is restricted to only include observations older than the age specified in each column. Inst ${ }_{c}$ is the probability of being treated by the 1985 reform, the variable ranges from 0 to 1 . Sample includes women in birth cohorts from 1950 to 1980 . The sample

includes respondents who cannot specify their birth month or year, these data are imputed for them by the DHS. All regressions include a cubic for age, a cubic three-part time trend, and fixed effects for quarter of birth, ethnicity, and type of childhood residence. Each regression is weighted by sampling weights from the DHS, and standard errors are clustered at the birth cohort (year and quarter) level. 
Table A8 - Reduced-form: Use of Contraception

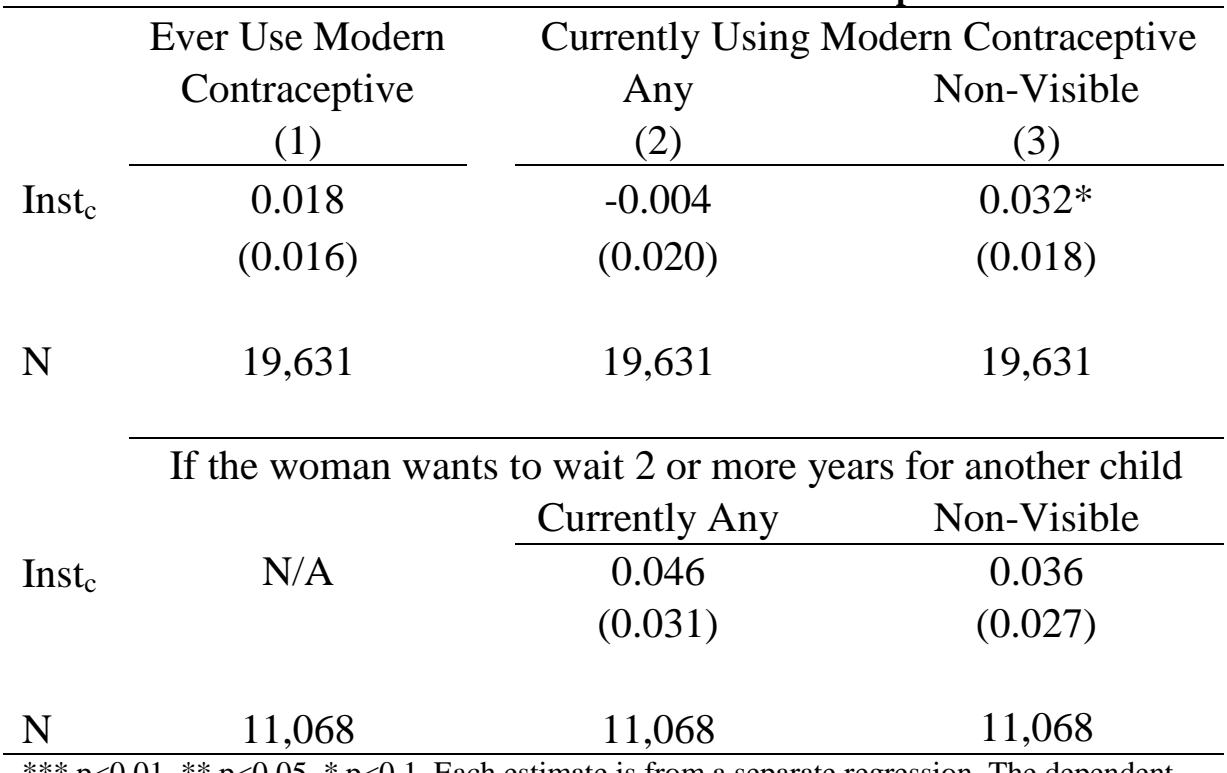

$* * * \mathrm{p}<0.01, * * \mathrm{p}<0.05, * \mathrm{p}<0.1$. Each estimate is from a separate regression. The dependent variable in column one is equal to one if the woman reports ever using a modern contraceptive method, zero otherwise. In the second column the dependent variable is equal to one if the respondent reported currently using a modern contraceptive method at the time of the survey, and zero otherwise. The last column's dependent variable is equal to only if the current contraception being used is an IUD, injection, or Norplant. The lower panel only includes women who report wanting to wait at least two years before their next child. Inst ${ }_{c}$ is the probability of being treated by the 1985 reform, the variable ranges from 0 to 1 , calculated using pre-reform enrollment data. The sample is restricted to only women in birth cohorts from 1950 to 1980 . All regressions include a cubic for age, a quadratic quarterly time trend, and fixed effects for quarter of birth, ethnicity, and type of childhood residence. Each regression is weighted by sampling weights from the DHS, and standard errors are clustered at the birth cohort (year and quarter) level. 